\title{
Underwater Photogrammetric Recording at the Site of Anfeh, Lebanon
}

\author{
Lucy Semaan and Mohammed Saeed Salama
}

\begin{abstract}
This chapter considers the application of underwater photogrammetry to record and document the underwater cultural heritage at the site of Anfeh in North Lebanon. Although photogrammetry has become a standard procedure in the field of maritime archaeology worldwide, this is the first use of this recording method in the country. The research context is presented, followed by the methodology adopted according to the particularities of the site and then the results of work undertaken over two campaigns: one in 2016 and one in 2017. The main aims in this chapter are to demonstrate the advantages of a low-cost and time-effective method of documenting sites, where the funding prohibits the use of more expensive geophysical equipment. The application of multi-image photogrammetry as a recording technique at Anfeh has merit in providing global access to artefacts in their in situ context. The results generated from 3D data were particularly informative to the study of a substantial collection of anchors of different types and sizes, without removing them from their underwater context. By calculating volume from the 3D scan, an estimation of the weight of these could be thus achieved and will serve in future analysis of the vessels plying the maritime routes at Anfeh.
\end{abstract}

\section{Keywords}

Underwater archaeology · Maritime material culture . Anchors $\cdot$ Eastern Mediterranean

L. Semaan $(\bowtie)$

Department of Archaeology and Museology,

University of Balamand, Al Kurah, Lebanon

e-mail: lucy.semaan@balamand.edu.lb

M. S. Salama

Alexandria Centre for Maritime Archaeology \& Underwater

Cultural Heritage, Alexandria University, Alexandria, Egypt

\subsection{Introduction}

Documentation is an intrinsic part of the archaeological process and presents innate challenges when research takes place in a submerged setting. Indeed, underwater archaeologists are faced with several constraints-not encountered in terrestrial archaeology - such as maximizing bottom time during each dive, the depth of the operations, as well as the ambient conditions of visibility, currents, and temperature. Underwater surveying methods using photography have developed substantially in the last few decades, and one such application, multi-image photogrammetry, has become a commonly used recording tool.

In lay terms, photogrammetry is defined as a process for taking measurements from photographs. However, multiimage photogrammetry and its related applications are much wider in scope as they breach the spatial and temporal limitations encountered when working under water, and also constitute a dissemination tool that fosters accessibility and hermeneutic discussions about the archaeological material. The nature, range, and development of photogrammetry go beyond the scope of this chapter and have been argued elsewhere (Balletti et al. 2016; Costa et al. 2015; Gawlik 2014; Green et al. 2002; Drap 2012; Polzer and Casaban 2012; McCarthy 2014; McCarthy and Benjamin 2014; Van Damme 2015; Yamafune et al. 2016; and the various chapters in this volume). Notably, McCarthy $(2014,176)$ stressed the potential of this technique as 'a practical and cost-effective method for accurate survey and as a tool for community engagement with heritage.' Also, from the perspective of applying such a technology to the documentation of shipwrecks (Balletti et al. 2015, 2016; Skarlatos et al. 2012, 2014) and underwa- 
ter sites (Bruno et al. 2015), and even for deep-sea underwater surveying (Drap et al. 2015), such a technology represents the opportunity to transpose the study of and accessibility to underwater cultural heritage from the marine environment onto dry land in a non-intrusive manner.

This chapter details the application of multi-image photogrammetry at Anfeh, Lebanon in an academic context and research into the maritime cultural landscape of Anfeh. ${ }^{1}$ The impact of such a technology in Lebanon is enhanced by the fact that it is the first endeavour of its kind in the country. To the authors' knowledge at present, no other research project pertaining to underwater archaeology has applied 3D photogrammetric recording to the documentation of the Lebanese underwater cultural heritage.

\subsubsection{Context of the Research}

The coastal town of Anfeh is located approximately $70 \mathrm{~km}$ north of Beirut and $15 \mathrm{~km}$ south of Tripoli. It is bordered by the village of Chekka and the Barghoun River to the south; to the north, by the agricultural area of Hraishi and the village of Qalamoun; and to the east by the villages of Barghoun and Zakroun (Fig. 5.1). Anfeh extends westwards to the Mediterranean Sea by a 400-metre long and 120-wide peninsula (Fig. 5.2). The latter, Ras al-Qalaat, is roughly oriented on a NNW-SSE axis while rising some $14 \mathrm{~m}$ above mean sea level (MSL). Three rock-cut moats separate it from the mainland at its easternmost limit and are carved on a north-south axis roughly perpendicular to the peninsula (Fig. 5.3) (Chaaya 2016, pp. 281-282; Lawrence 1988, 28; Nordiguian and Voisin 1999, 381; Panayot-Haroun 2015, 399). The coastline north of Ras al-Qalaat is exposed as it offers no lee from the dominant SW winds. It consists of cliffs that drop in places onto a narrow rocky shore that is hazardous for seafaring. Closer to the peninsula, the coastline forms two large well-protected shallow bays - the Nhayreh Bay and the bay of Ras al-Safi-that offer natural havens (Fig. 5.4). Due to coastal urbanisation that started developing in the 1980s, both sides of the Nhayreh Bay are occupied by modern beach resorts. This leaves a narrow space in the bottom of the bay for the present-day modest fishermen's harbour. To the south of Ras al-Qalaat, the rocky shoreline is low-lying and consists of a small cove with an open bay that are suitable for anchoring and landing places when the northerly winds blow, being in the lee of the promontory.

Recent terrestrial excavation and survey work on the peninsula and its hinterland by the Department of Archaeology

\footnotetext{
${ }^{1}$ This research project constitutes Semaan's 3-year post-doctoral fellowship (2015-2018) at UoB with a grant from the Honor Frost Foundation and UoB. Hence, all fieldwork related activities are financed by Semaan's research allowance.
}

and Museology (DAM), ${ }^{2}$ University of Balamand (UoB), suggests an occupation of the promontory of Ras al-Qalaat and of the modern town of Anfeh that extends most likely from the Early Bronze Age to the Ottoman period (PanayotHaroun 2015, 2016). In May 2016 and in September 2017, $\mathrm{DAM}^{3}$ led a one month detailed recording of underwater cultural material at the site through multi-image photogrammetry. This was preceded by a three week underwater visual survey undertaken in 2013 in the waters around Ras al-Qalaat and off the north and south coastal stretches of the modern town that aimed at assessing the underwater archaeological potential at Anfeh (Fig. 5.5) (Semaan 2016; Semaan et al. 2016).

Considering the logistical constraints in terms of time, and human and financial resources, the 2013 preliminary survey also laid the groundwork for the subsequent underwater photogrammetry surveys. The later surveys mapped submerged relevant archaeological features and artefacts, and generated accurate in situ 3D records of these, while reducing the time and cost of archaeological survey work. Indeed, this low-cost and user-friendly method for acquiring highresolution datasets is well suited for low-budget research since, traditionally, underwater archaeological research projects are associated with high financial and logistical costs. At Anfeh, these detailed datasets constitute base-line knowledge of its seabed, which is hitherto understudied, and offers first-hand documentation for further research.

An innovative application has been the calculation of volume, and by extrapolation the weight, of in situ stone anchors based on the density of the material associated with each stone type (Table 5.3). Indeed, the standard practice of stone anchor recording or 'anchorology', set by pioneer Honor Frost in Mediterranean archaeology (Frost 1997), favours weight as a key typological parameter, which can reflect both the antiquity of anchors and the size of the carrying vessel. Underwater photogrammetry allows a much more accurate calculation of anchor weight, as recently demonstrated by Fulton et al. (2016). Moreover, the site's submerged archaeological material is vulnerable to looting - thus multi-image photogrammetry allows close monitoring and is a means to mitigate potential losses.

\footnotetext{
${ }^{2}$ The Anfeh Project is led by Nadine Panayot-Haroun, Head of DAM. ${ }^{3}$ The teams were supervised by Lucy Semaan (UoB) and comprised maritime archaeologists Rupert Brandmeier (Ludwig-MaximiliansUniversity), Clara Fuquen (University of Southampton), Menna-Allah Ibrahim, Ziad Morsy, Mohammad Saeed, and Maii Tarek (University of Alexandria), Enzo Cocca and Salvatore Colella (Università degli Studi di Napoli L'Orientale); archaeologist Hadi Choueiri; as well as Lebanese divers Hussein al-Hajj, Mario Kozaily, Serge Soued, Shadi Zein, and Elie Semaan who intermittently joined the team on a voluntary basis.
} 


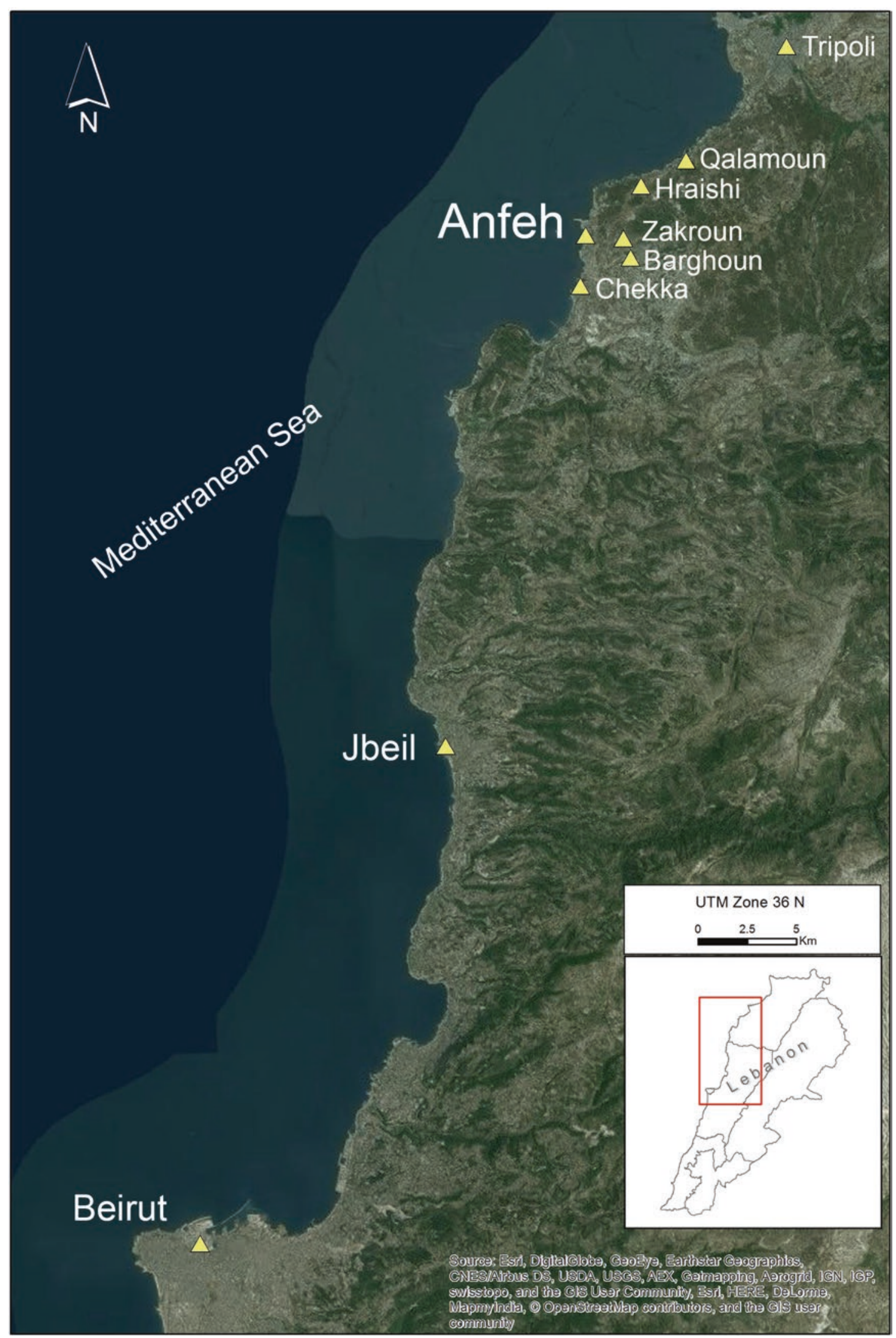

Fig. 5.1 A map of the location of Anfeh and neighbouring areas (C. Safadi) 


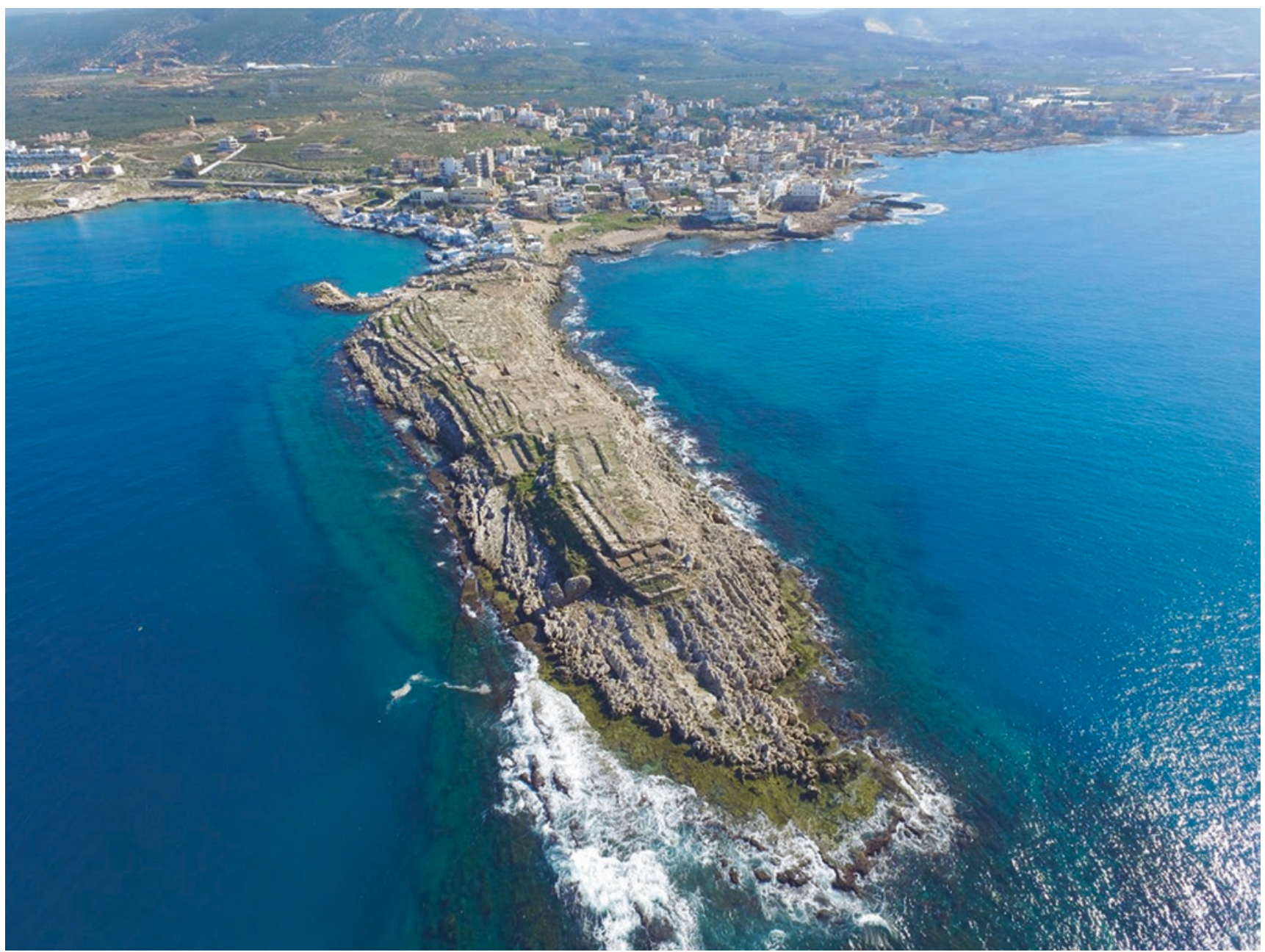

Fig. 5.2 Aerial image of Ras al-Qalaat extending westwards into the Mediterranean Sea (R. Tanissa)

\subsubsection{Recorded Archaeological Cultural Heritage at Anfeh}

The targeted artefacts and features recorded using multiimage photogrammetry at Anfeh can be divided into four categories:

1. Onshore ramps or slipways: There are two slipways on the Ras al-Qalaat promontory that were recorded via photogrammetry and one further east on the southern coast of Ras al-Safi bay; while the fourth is located on the southern coast of Anfeh;

2. Anchors recovered from the seabed: 12 anchors were retrieved in 2013 during the underwater visual survey for the purpose of dating and typology. Another two were recovered in 2016. The 14 anchors were recorded via photogrammetry on land;

3. Underwater anchors: These 17 anchors were recorded in situ in 2013 and 2016 and were left under water. They either constitute isolated finds or anchors located in groups adjacent to each other. The team defined the groups and zones to be covered according to the organic distribution of these artefacts; and

4. Underwater masonry blocks: These were mainly recorded previously in 2013. As with the anchors, they were also found either as isolated finds or in larger clusters.

\subsubsection{Methodology}

The authors used the Agisoft Photoscan/Metashape Professional edition ${ }^{\circledR}$ software to record and map underwater material such as masonry blocks and anchors as well as coastal features, mainly the above-mentioned four slipways; and to produce orthogonal projections, sections, plans and drawings as supporting visual documentation in the framework of researching the maritime cultural landscape of Anfeh. One of the future goals is to combine the 3D rendering of anchors and masonry blocks with other digital techniques to produce a virtual tour of the modelled areas for the general public, espe- 


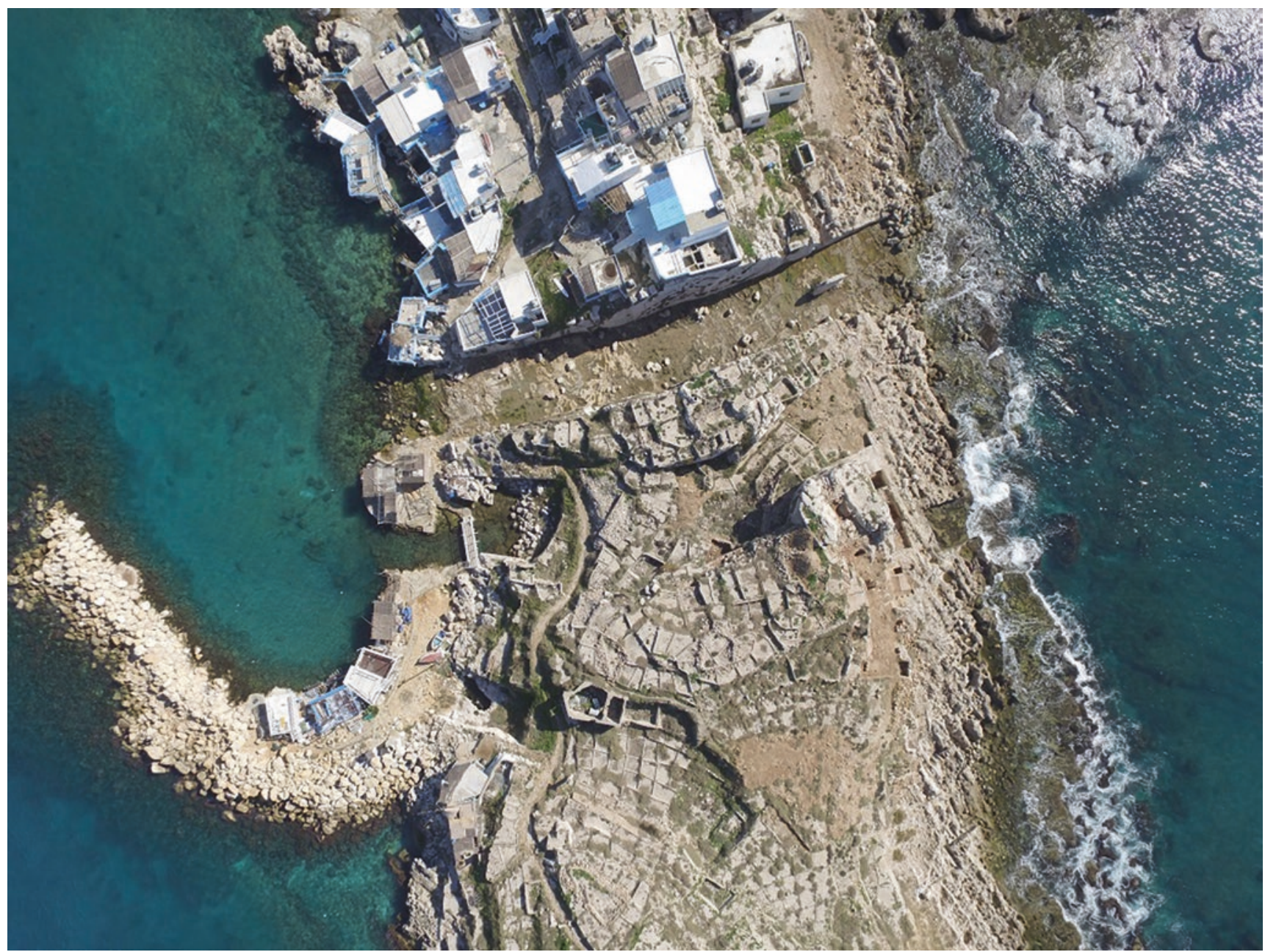

Fig. 5.3 Aerial image of the three moats on the eastern side of Ras al-Qalaat (R. Tanissa)

cially the non-divers, so they gain an appreciation of the underwater cultural heritage at Anfeh (Fig. 5.6). These activities are part of a wider workflow that was inspired by Yamafune et al. (2016). As this still is a work in progress, this chapter will discuss the procedures of underwater photography, photogrammetry, and orthophotos illustrated in the workflow diagram.

\subsection{Underwater Photography}

\subsubsection{Equipment}

During the 2016 and 2017 seasons, ${ }^{4}$ the team used four different underwater photography systems for data collection,

\footnotetext{
${ }^{4}$ Images for the anchors, the masonry blocks in S7, S8 and U9 were captured in 2016 by Mohammad Saeed and Ziad Morsy, and the ones for the masonry blocks located in R10 and T8, T9 were captured in
}

in order to compare and optimise results (Table 5.1): (1) GoPro HERO4 Black Edition with its stock underwater housing; (2) Canon PowerShot G15 compact camera, with an underwater Fantasea housing (Fig. 5.7: to the right); (3) Canon EOS 70D DSRL equipped with a Canon 20-mm lens that provides a great depth-of-field while getting closer to the target. The camera was set in an IKELITE Underwater TTL housing, mounted on an aluminium tray with dual quick release handles, and with a modular 8 in. dome with 2.75-in. lens extension. The whole kit was completed with two DS-161 strobes and their light diffusers. The Ikelite housing had a hemispherical glass in front of the lens in order to minimize the refraction error due to the water/glass interface (Drap 2012, 115), and thus generate sharper image corners caused by the use of a wide angle lens (Fig. 5.7: to the left) (Yamafune et al. 2016, 7); and (4) Sony DSC-RX100 com-

2017 by Salvatore Colella and processed by Enzo Cocca (See Archaeological Survey Results below). 


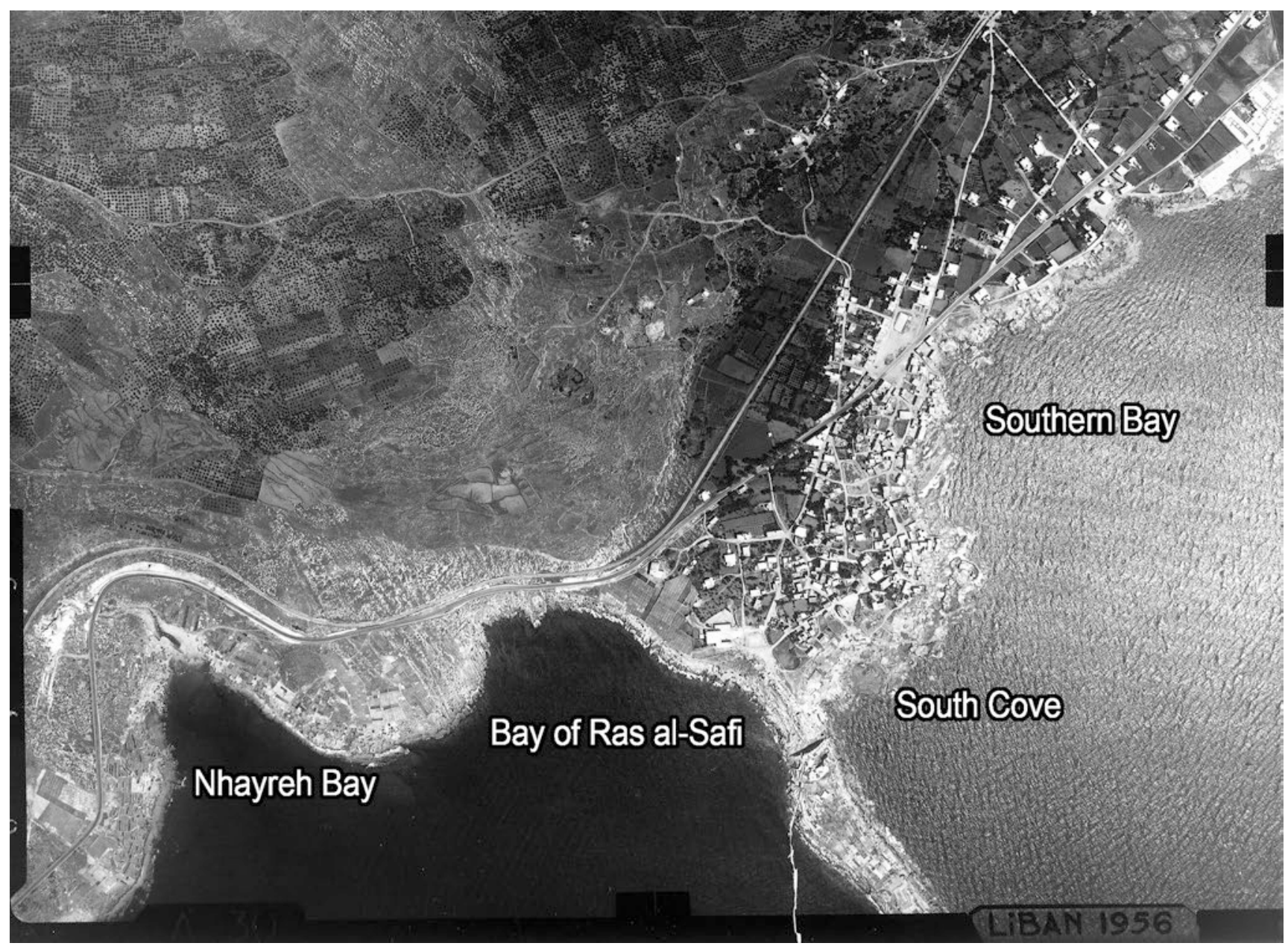

Fig. 5.4 Aerial image of Ras al-Qalaat and its north and south bays, taken in 1956. (@Directorate of Geographical Services, Ministry of Defence, Lebanon, 1/5000, Photo 494, Mission 1/100; Property of the Department of Archaeology and Museology at UoB)

pact camera set in a Nauticam Underwater housing working with an INON UWL-H100 wide conversion lens type 2.5

A high performance computer is usually required to run multi-image photogrammetry software as it analyses a substantial amount of images (McCarthy 2014, 177). Therefore, the team used a MSI GT80 Titan SLI high-end gaming laptop with a 2.70-GHz Intel Core i7-6820HQ CPU, 32 GB of RAM and Dual NVidia GeForce GTX video card, which successfully dealt with the large photogrammetric datasets.

\subsubsection{Data Collection}

First, the various targeted areas were marked and delimited: either visually using natural markers on the seabed as references for small surfaces, or with ropes and rods for larger surfaces. The features and artefacts were then cleaned of

${ }^{5}$ This system was used in 2017 by Salvatore Colella while the previous three systems were used in 2016. debris and algae and then tagged. A 1-m scale bar, or sometimes two, were placed next to objects. The scale bars were graded in black and white every $10 \mathrm{~cm}$. Then, a set of clear and well-exposed images was taken of the targeted area from free positions, with a considerable overlap of over $50 \%$ between images. As Drap $(2012,114)$ argues: 'The key factor of this method is redundancy: each point of measured space must be seen in at least three photographs.' This is also done to optimize results in Agisoft Photoscan/Metashape as each image is compared to every other image. The settings of the cameras, and particularly the lens zoom, were not changed during data capture.

The series of photos were taken with an estimated field of view of $45-70^{\circ}$, and from different positions while swimming in a circular and/or a zigzag pattern. When the objects and their wider landscape were being recorded, the diver covered the limits of the landscape first. Indeed, several oblique photos were taken around each location/group of artefacts and features to provide a wider coverage. Subsequently and in a continuous mode, the diving photog- 


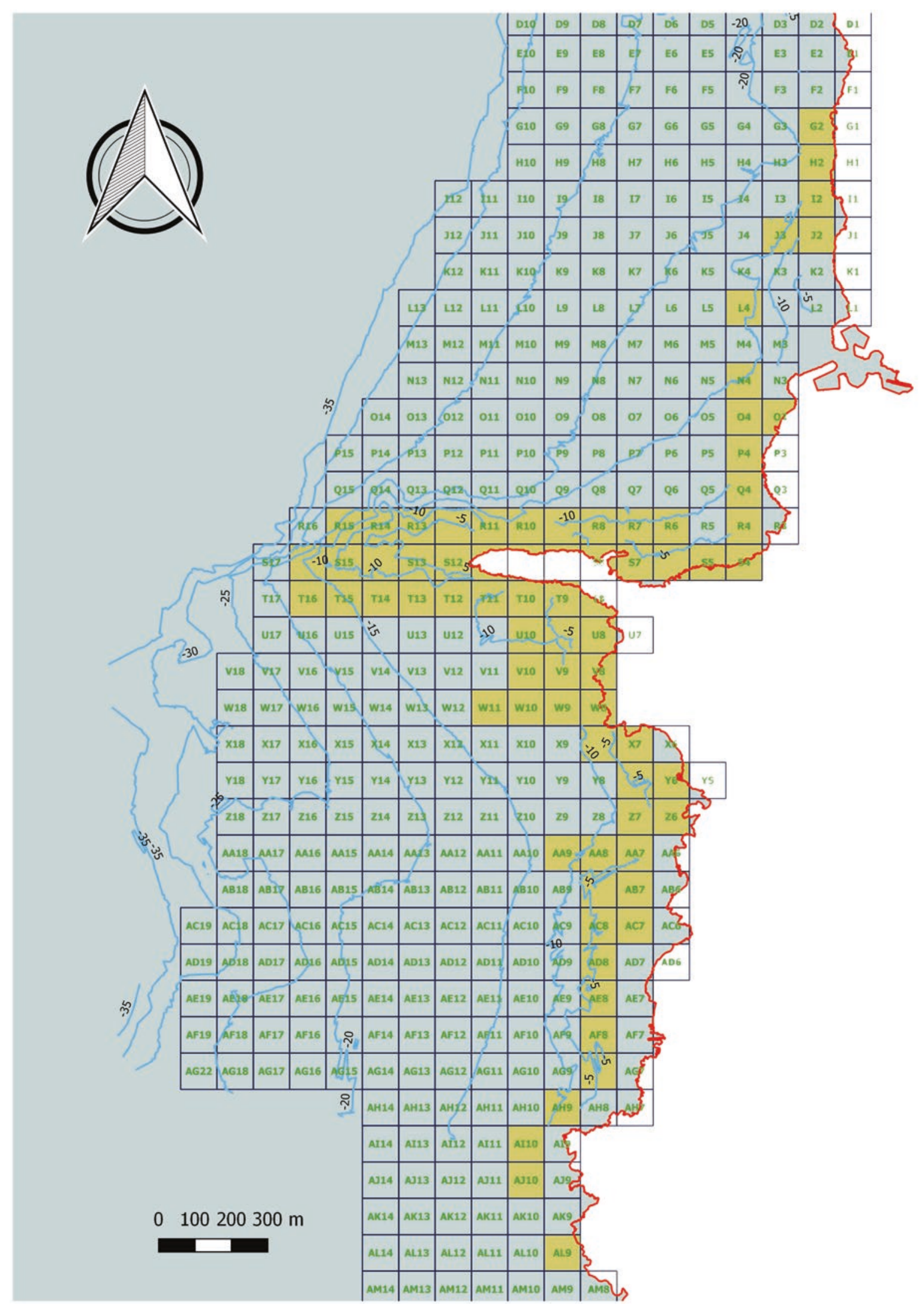

Fig. 5.5 Bathymetry map of Ras al-Qalaat and Anfeh's coastline showing the grid system and the areas covered during fieldwork from 2013 to 2017 (Produced for the underwater visual survey at Anfeh by the Institute of Environment (UoB) and modified in GIS by C. Safadi and E. Cocca) 
Fig. 5.6 Workflow for the multi-image photogrammetry applied to Anfeh's underwater cultural heritage following the methodology set by Yamafune et al. (2016) (L. Semaan modified from Yamafune et al. 2016:Figure 1)

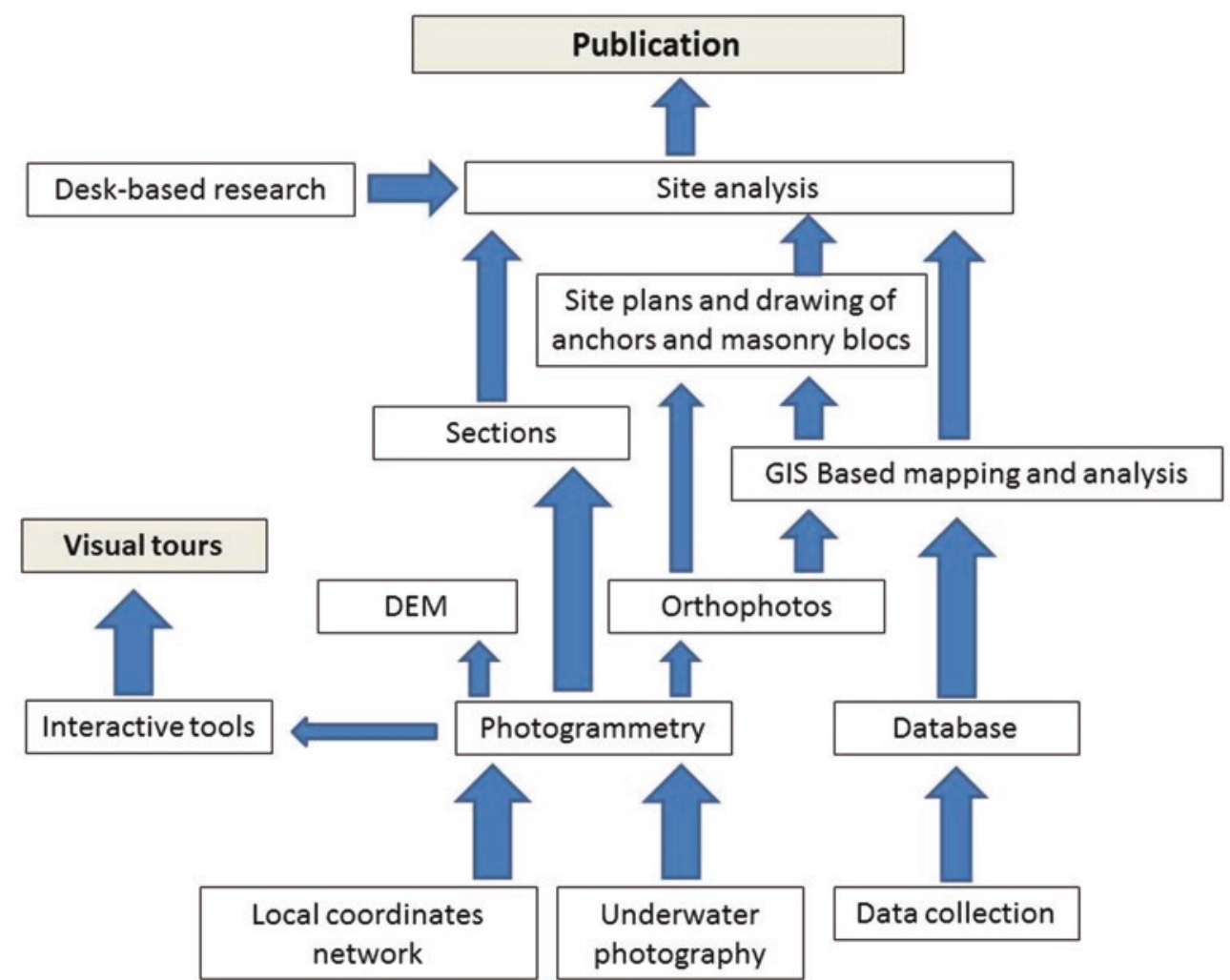

Table 5.1 Summary table of the characteristics of each camera system

\begin{tabular}{|c|c|c|c|c|}
\hline Camera systems & GoPro HERO4 black & Canon PowerShot G15 & Canon EOS 70D DSRL & Sony RX-100 \\
\hline Image sensor & CMOS & CMOS 1/1.7" & $\begin{array}{l}\text { APS-C 'Dual Pixel CMOS } \\
\text { AF' }\end{array}$ & Exmor CMOS sensor 1" \\
\hline Sensor size & $1 / 2.3^{\prime \prime}$ & $41.51 \mathrm{~mm}^{2}(7.44 \times 5.58 \mathrm{~mm})$ & $\begin{array}{l}337.5 \mathrm{~mm}^{2}(22.50 \times \\
15.00 \mathrm{~mm})\end{array}$ & $116.16 \mathrm{~mm}^{2}(13.2 \times 8.8 \mathrm{~mm})$ \\
\hline Resolution & $\begin{array}{l}12 \mathrm{MP}, 4000 \times 3000 \\
\text { pixels }\end{array}$ & $12 \mathrm{MP}, 4000 \times 3000$ pixels & $20.2 \mathrm{MP}, 5472 \times 3648$ pixels & $20.2 \mathrm{MP}, 5472 \times 3648$ pixels \\
\hline Focal length & Wide-angle lens & $\begin{array}{l}28-140 \mathrm{~mm} \text { (equivalent at } \\
35 \mathrm{~mm} \text { to } 6.1-30.5 \mathrm{~mm} \\
\mathrm{~F} / 1.8-2.8)\end{array}$ & $\begin{array}{l}18-135 \mathrm{~mm} \text { (equivalent at } \\
35 \mathrm{~mm} \text { to } 29-216 \mathrm{~mm}, \\
\mathrm{~F} / 3.5-5.6)\end{array}$ & $\begin{array}{l}10.4-37.1 \mathrm{~mm} \text { (equivalent at } \\
35 \mathrm{~mm} \text { to } 28-100 \mathrm{~mm} \text {, } \\
\mathrm{F} / 1.8-4.9)\end{array}$ \\
\hline \multirow[t]{2}{*}{ ISO range } & \multirow[t]{2}{*}{6400 (max) } & \multirow[t]{2}{*}{$80-12800$} & 100-12800 standard & \multirow[t]{2}{*}{$125-6400$} \\
\hline & & & 25600 expanded & \\
\hline Zoom ratio & - & $5 \times$ & $7.50 \times$ & $3.6 x$ \\
\hline Aperture range & $\mathrm{F} / 2.8$ & $\mathrm{~F} / 1.8-\mathrm{F} / 2.8$ & $\begin{array}{l}\mathrm{F} / 3.5-\mathrm{F} / 22 \text { (wide) } \\
-\mathrm{F} / 5.6-\mathrm{F} / 36 \text { (tele) }\end{array}$ & F/1.8 (wide)-F/4.9 (tele) \\
\hline Shutter speed & $2 \mathrm{~s}-1 / 8192 \mathrm{~s}$ & $15 \mathrm{~s}-1 / 4000 \mathrm{~s}$ & $30 \mathrm{~s}-1 / 8000 \mathrm{~s}$ & $30 \mathrm{~s}-1 / 2000$ \\
\hline Flash & & Built-in & Built-in & Built-in \\
\hline $\begin{array}{l}\text { Supported } \\
\text { operating system }\end{array}$ & $\begin{array}{l}\text { Windows } 7,8,8.1 \text {, } \\
\text { Mac OS X } 10.8\end{array}$ & $\begin{array}{l}\text { Windows XP, Vista, } 7,8,10 \text {, } \\
\text { Mac OS X }\end{array}$ & $\begin{array}{l}\text { Windows XP, Vista, 7, 8, 10, } \\
\text { Mac OS X }\end{array}$ & $\begin{array}{l}\text { Windows XP, Vista, } 7,8,10 \text {, } \\
\text { Mac OS X }\end{array}$ \\
\hline \multirow{2}{*}{$\begin{array}{l}\text { Operating } \\
\text { environment }\end{array}$} & \multirow{2}{*}{$\begin{array}{l}\text { Max depth: } 60 \mathrm{~m}, \max \\
\text { temperature: } 50{ }^{\circ} \mathrm{C}\end{array}$} & Temperature: $0^{\circ}-40^{\circ} \mathrm{C}$ & Temperature: $0^{\circ}-40^{\circ} \mathrm{C}$ & \multirow[t]{2}{*}{ Temperature: $0^{\circ}-40^{\circ} \mathrm{C}$} \\
\hline & & Humidity: $10-90 \%$ & Humidity: $0-85 \%$ & \\
\hline Dimensions & $41 \times 59 \times 21 / 30 \mathrm{~mm}$ & $\begin{array}{l}107 \times 76 \times 40 \mathrm{~mm} \text { (without } \\
\text { housing) }\end{array}$ & $\begin{array}{l}139 \times 104 \times 79 \mathrm{~mm} \text { (without } \\
\text { housing and strobes) }\end{array}$ & $\begin{array}{l}101.6 \times 58.16 \times 1.41 \mathrm{~mm} \\
\text { (without housing) }\end{array}$ \\
\hline Weight & $\begin{array}{l}88 \mathrm{~g}(152 \mathrm{~g} \text { with } \\
\text { housing })\end{array}$ & $352 \mathrm{~g}$ (without housing) & $\begin{array}{l}755 \mathrm{~g} \text { (without lens dome, } \\
\text { housing, and strobes) }\end{array}$ & 213 g (body only) \\
\hline
\end{tabular}


Fig. 5.7 Two of the camera systems used: to the left, the Canon EOS 70D DSRL with the Ikelite housing and to the right the Canon PowerShot G15 with the Fantasea housing (L. Semaan)
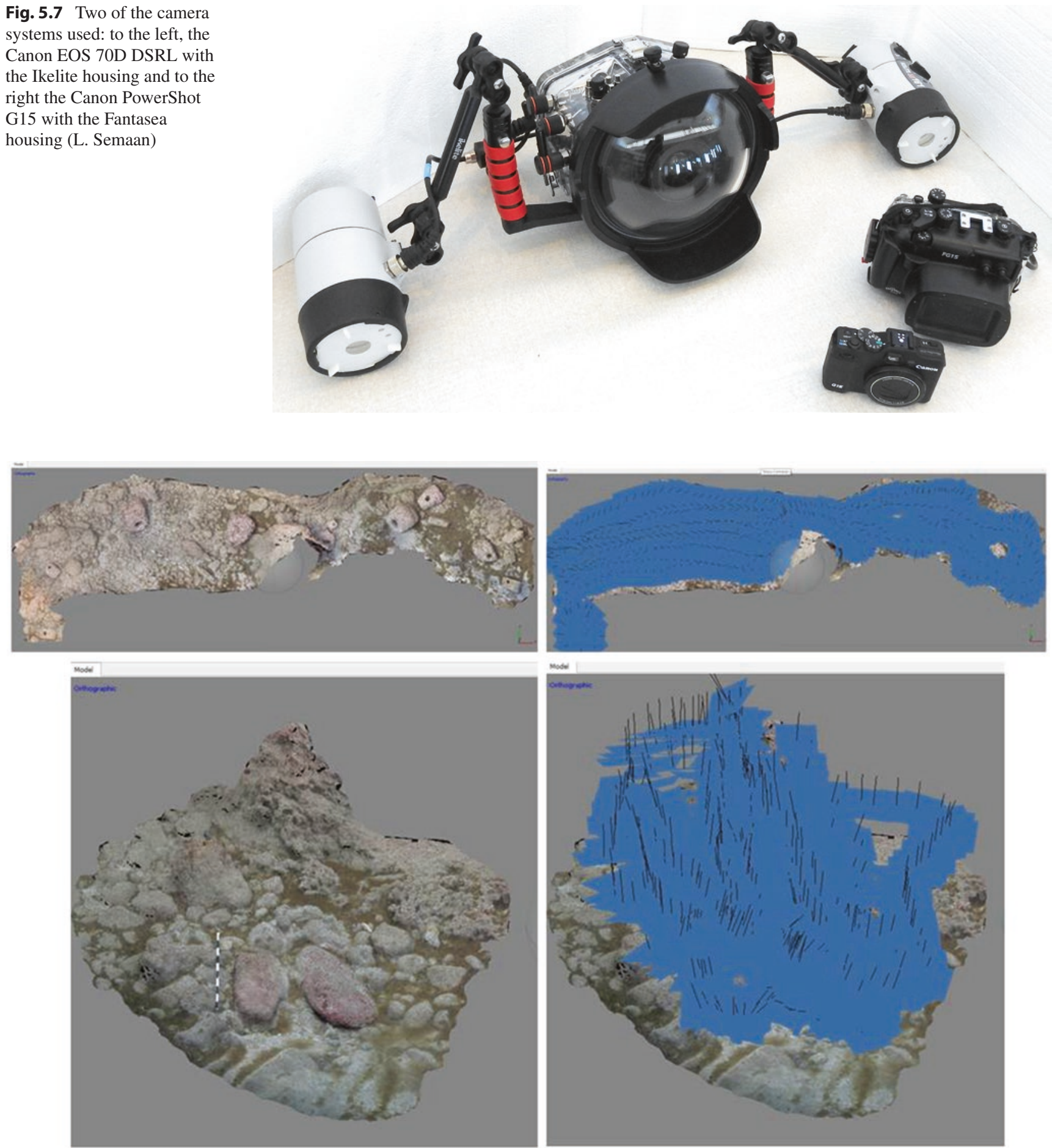

Fig. 5.8 Examples of the camera positions covering two groups of anchors (top: Group 2 and 3), and two well-weathered masonry blocs (bottom) (Photos: M. S. Salama)

rapher captured a series of pictures that covered the object up-close to a distance above object between a range of 0.5$1.5 \mathrm{~m}$ with a $360^{\circ}$ capture around the object itself (Fig. 5.8).
During data acquisition the GoPro camera did not provide clear high-resolution images. The focal length of its lens is quite small, and as a wide angle fisheye, caused important 
distortions (Capra et al. 2015, 71). ${ }^{6}$ The authors decided, therefore, to forego capturing images with this system and focused on the other two higher-end systems:

\subsubsection{Data Collection with CanonG15}

This system was light-weight, compact, and easy to use. Hence it did not cause major issues for the team during data acquisition. This system has a $28-\mathrm{mm}$ equivalent lens ( $f$ : lens focal length $)$ and a camera with sensor sizes of $7.6 \mathrm{~mm}\left(S_{x}\right.$ : sensor size in $x)$ by $5.7 \mathrm{~mm}\left(S_{y}\right.$ : sensor size in $\left.y\right)$. Swimming on an average of $1 \mathrm{~m}$ ( $d$ : distance from the object $)$ above the targeted sites, and considering the relational equation for producing good quality images $\mathrm{C}_{\mathrm{x}=} \frac{\mathrm{Sx} \times \mathrm{d}}{\mathrm{f}}$ (Yamafune et al. 2016), the diver was able to cover a rectangular area of $0.27 \mathrm{~m}\left(C_{x}\right.$ : coverage in $\left.x\right)$ by $0.20 \mathrm{~m}\left(C_{y}\right.$ : coverage in $\left.y\right)$ on each shot. Perhaps the one downside of this system, however, was that the white balance had to be manually evaluated depending on the depth of the targeted area for JPEG acquisition. For example, one area extended between a depth of 4 and $10 \mathrm{~m}$ which complicated the finding of the right white balance underwater and optimising the quality of the images.

\subsubsection{Data Collection with Canon EOS 70D}

Using this system enabled the team to obtain clear shots with true colours and a good exposure of the site. Also, this configuration allowed for a wider coverage than the Canon G15, because a wide angle lens could be used, thus ensuring more time-saving swimming plans: with a $20-\mathrm{mm}$ lens $(f)$, a sensor of $22.5\left(\mathrm{~S}_{\mathrm{x}}\right)$ by $15 \mathrm{~mm}\left(\mathrm{~S}_{\mathrm{y}}\right)$, and while swimming on an average distance of $1 \mathrm{~m}(d)$ above the targets, the diver was able to capture shots equating to a rectangular area of $1.12 \mathrm{~m}\left(\mathrm{C}_{\mathrm{x}}\right)$ by $0.75 \mathrm{~m}\left(\mathrm{C}_{\mathrm{y}}\right)$. The Canon EOS 70D with its Ikelite housing system, however, is quite bulky to manipulate, and the strobes would only capture about $300-600$ photos in a single dive, depending on the flash power.

\subsubsection{Data Collection with Sony DSC-RX100}

This system was similar to the Canon G15 as it was also light and easily manoeuvred underwater. It captured photos with the lens at $12.18 \mathrm{~mm}(f)$ and a sensor size of $13.2 \mathrm{~mm}\left(S_{x}\right)$ by $8.8 \mathrm{~mm}\left(S_{y}\right)$. Swimming on an average of $1 \mathrm{~m}(d)$ above the targeted sites, the diver was able to cover a rectangular area of $1.08 \mathrm{~m}\left(C_{x}\right)$ by $0.72 \mathrm{~m}\left(C_{\mathrm{y}}\right)$ respectively on each shot.

\subsubsection{Image processing}

Upon acquisition, the images were downloaded to the computer, sorted, and tagged. This was done using Adobe Bridge,

${ }^{6}$ This is, however, not always the case as explained by Van Damme (2015, p 236). which is a digital asset management software that can import and bulk rename batches of pictures, while granting easy access to metadata. Tagging pictures was done systematically, by filling the related fields of the software accordingly: 'Area code _Dive Log_ Artefact ID_Material/Subject_ Date_Photo number'. The Area code refers to the square individual number of the survey grid; the Dive Log is the number of the dive related to collecting the related picture; Artefact ID stands for the inventory name of the archaeological object; Material is the nature of the artefact photographed such as masonry, anchor, pottery, etc., and the subject refers to pictures showing people in action or the underwater environment for example; the date relates to the date when the pictures were taken; and the photo number is the serial number automatically generated by the camera used.

The images collected needed to be processed before they could be used to construct accurate 3D photo models. This was done through using Adobe Lightroom 5 and Photoshop CS5 to edit the colour balance, the contrast, and the brightness properties of the photos. The authors preferred not to greatly modify the colours of the images, in order to stay faithful to the actual state of the object and the landscape.

\subsection{Multi-image Photogrammetry}

Subsequent to processing, overlapping digital images taken from different viewpoints were loaded in one batch into Agisoft Photoscan/Metashape, which analyses each picture, automatically detects matching correlated features in unordered picture collections, and creates 3D models from still images. At Anfeh, this software was used to develop 3D models of the collected data, as it proved to be reliable and easy to use in its automation and interface. Also, Agisoft Photoscan/Metashape has the advantage of rendering the camera calibration and bundle adjustments obsolete. The MSI laptop used was able to process quite dense point clouds which were limited between a few hours to processing overnight.

The camera and housing system used in 2017, however, the Sony DSC-RX100, needed calibration. A plastic A4 checkered sheet was printed and plunged in the water. Subsequently and with the camera at the same focal length used for the underwater photogrammetry, team members Enzo Cocca and Salvatore Colella took photos in order to frame just the sheet in various settings. Generally, 10-15 photos were taken after each photogrammetry immersion. They were then processed with Agisoft Lens software in order to calibrate the camera system. Once this was done, the exported.xml file was used in Agisoft Photoscan/Metashape to correct the errors of the images. Below is a list of the calibration parameters used in Agisoft Photoscan/Metashape to align the images: 
- fx, fy: the $x$ and $y$ dimensions of the focal length measured in pixels;

- cx, cy: coordinates of the main points, i.e. the coordinates of the optical axis intersection with the sensor plane;

- skew: skew transformation coefficient;

- $\mathrm{k} 1, \mathrm{k} 2, \mathrm{k} 3, \mathrm{k} 4$ : radial distorsion coefficients; and

- p1, p2, p3, p4: tangential distortion coefficients.

There are several tasks required by Agisoft Photoscan/ Metashape in order to load and process images, and produce 3D models (Agisoft 2016, 8). Below are the ones that were applied specifically during the multi-image photogrammetric process at Anfeh:

1. Loading photos into the software and aligning them which results in creating sparse point clouds and showing camera positions;

2. Building dense point cloud which is based on the estimated camera positions and the captured pictures;

3. Building mesh, that is, generating a 3D polygonal model that represents the object surface based on the dense point cloud (Agisoft 2016, v);

4. Generating texture and applying it to the mesh; and

5. Exporting orthomosaic, 3D PDF files, and Digital Elevation Models (DEM).

The general settings for processing the various 3D models are compiled in Table 5.2.

As previously mentioned, the nature of the recorded material at Anfeh varied between on-land and underwater material culture. ${ }^{7}$ During the 2016 season a total of about 30,000 photos were captured, including a total of 23 dives dedicated to the task of underwater photogrammetry equating to a total of $24 \mathrm{~h}$ of shooting underwater. So far, the total days for processing data are equivalent to 65 days. Meanwhile during the 2017 season, a total of 1762 photos were captured during a total of three dives which equated to about $4 \mathrm{~h}$ of shooting underwater. The total time spent processing these was $8 \mathrm{~h}$ and $4 \mathrm{~min}$.

Table 5.2 General settings followed for all 3D models

\begin{tabular}{l|l}
\hline Align photos & Accuracy/high-medium \\
\cline { 2 - 2 } & Pair preselecting/generic \\
\hline \multirow{2}{*}{ Build dense cloud } & Quality/high-medium \\
\cline { 2 - 2 } & Depth filtering/mild-moderate \\
\hline \multirow{2}{*}{ Build mesh } & Polygon count/medium-low \\
\cline { 2 - 2 } & Interpolation/enabled \\
\hline Build texture & Mapping mode/generic \\
\cline { 2 - 2 } & Blending mode/mosaic \\
\hline
\end{tabular}

${ }^{7}$ See 'Recorded Coastal and Underwater Cultural Heritage at Anfeh' section above.

\subsubsection{Orthophotos}

Subsequent to generating 3D models for each artefact or group of artefacts, orthophotos were extracted as 1:1 scaled top view photomosaics with Agisoft Photoscan/Metashape. These $2 \mathrm{D}$ images were captured in high quality and exported as JPEG formats. Decimated versions of these were also produced to facilitate their use in presentations and in other instances where highly accurate files were not needed. These are currently used as a basis for drawing and tracing 2D site plans in AutoCAD® software.

In the case of the isolated finds, the orthophotos were directly generated from the 3D model. In the case of the larger groups of finds-such as the different groups of anchors at the feet of the southern reef and the large area of masonry blocks on the north-eastern side of Ras al-Qalaathowever, the photomosaics were patched together from the different batches used in generating the photogrammetric models of the sites. In such instances, the batches were close enough to each other and there was sufficient overlap between each group. Therefore, the authors linked these batches by marking common points then aligning the chunks to each other according to these points.

\subsubsection{Export Adobe 3D PDFs}

The team was also able to able to export 3D models as 3D PDF format. One of the main advantages of generating such format files is the careful study of the material while reducing the time required for measurements underwater; as well as extrapolating measures and dimensions of artefacts taken at the office from the corresponding 3D PDF files (Tables 5.3 and 5.4).

\subsection{Archaeological Survey Results}

Since this chapter pertains mainly to underwater recording and photogrammetry, the related processes of recording submerged anchors and limestone masonry blocks lying on the seabed will be explained here. Indeed, the team was able to effectively obtain the accurate shapes, geometry, colour, measurements, and spatial distribution of the submerged artefacts.

\subsubsection{Isolated Anchors}

Several anchors were located during the 2013 and 2016 visual surveys, some of which were left in situ and recorded photographically for 3D photogrammetry. One example is a one-hole triangular anchor (AN.S12.004) of substantial 
Table 5.3 Measurements of the anchors mentioned in the text according to their 3D PDF files

\begin{tabular}{l|l|l|l|l|l}
\hline $\begin{array}{l}\text { Anchor } \\
\text { AN. S12 } \\
\text { 004 }\end{array}$ & $\begin{array}{l}\text { Length } \\
(\mathrm{cm})\end{array}$ & $\begin{array}{l}\text { Width } \\
(\mathrm{cm})\end{array}$ & $\begin{array}{l}\text { Thickness } \\
(\mathrm{cm})\end{array}$ & $\begin{array}{l}\text { Hole } \\
\text { diameter } \\
(\mathrm{cm})\end{array}$ & $\begin{array}{l}\text { Estimated } \\
\text { weight }(\mathrm{kg})\end{array}$ \\
\hline $\begin{array}{l}\text { AN. S11. } \\
273\end{array}$ & 35.7 & 20.8 & 36 & 22 & 337.82 \\
\hline $\begin{array}{l}\text { AN. S11. } \\
286\end{array}$ & 46.7 & 27.2 & 7 & $4.6-4.1$ & 8.56 \\
\hline $\begin{array}{l}\text { AN. S11. } \\
287\end{array}$ & 46 & 31.3 & 4.9 & 12.3 & 13.98 \\
\hline $\begin{array}{l}\text { AN. S11. } \\
288\end{array}$ & 47.2 & 30.1 & 4.8 & 16.4 & 12.54 \\
\hline $\begin{array}{l}\text { AN. S11. } \\
274\end{array}$ & 42.5 & 31.5 & 11.5 & 5.3 & 32.70 \\
\hline $\begin{array}{l}\text { AN. S11. } \\
291\end{array}$ & 45 & 30 & 10.5 & 8.5 & 29.33 \\
\hline $\begin{array}{l}\text { AN. S11. } \\
292\end{array}$ & 77.8 & 58.5 & 30.8 & 17.2 & 287.33 \\
\hline $\begin{array}{l}\text { AN. S11. } \\
293\end{array}$ & 76 & 64.6 & 35 & 24.7 & 334.95 \\
\hline $\begin{array}{l}\text { AN. T11. } \\
294\end{array}$ & 49 & 51.95 & 14.5 & 20.8 & 69.08 \\
\hline $\begin{array}{l}\text { AN. T11. } \\
295\end{array}$ & 23.6 & 20.1 & 12.5 & 4 & 12.46 \\
\hline $\begin{array}{l}\text { AN. T11. } \\
296\end{array}$ & 67.2 & 63.3 & 33 & 22.9 & 273.86 \\
\hline $\begin{array}{l}\text { AN. T11. } \\
297\end{array}$ & 64.3 & 41.5 & 20 & 14 & 108.63 \\
\hline $\begin{array}{l}\text { AN. T11. } \\
298\end{array}$ & 73.8 & 47 & 15.5 & 12.4 & 112.08 \\
\hline $\begin{array}{l}\text { AN. T11. } \\
299\end{array}$ & 37.9 & 31 & 7.2 & 4.5 & 18.02 \\
\hline $\begin{array}{l}\text { AN. T11. } \\
300\end{array}$ & 50 & 30 & 7.9 & 8.3 & 24.67 \\
\hline $\begin{array}{l}\text { AN. T10. } \\
146\end{array}$ & 57.6 & 38.8 & 19.7 & 9.9 & 91.82 \\
\hline
\end{tabular}

Table 5.4 Measurements of the masonry blocs mentioned in the text according to their 3D PDF files

\begin{tabular}{l|l|l|l}
\hline Block & Length $(\mathrm{cm})$ & Width $(\mathrm{cm})$ & Depth $(\mathrm{cm})$ \\
\hline AN. S8. 188 & 157 & 133 & 94.3 \\
\hline AN. S8. 189 & 190 & 124 & 102 \\
\hline AN. S8. 190 & 132 & 87.6 & 81.2 \\
\hline AN. S8. 191 & 157 & 120 & 86.9 \\
\hline AN. S8. 192 & 177 & 127 & 91.9 \\
\hline AN. U9. 240 & 100 & 32.2 & 12.2 \\
\hline
\end{tabular}

The measurements of AN.U9.240 are the ones taken in 2016 when the block was found half buried in sediments

dimensions (Table 5.3), that was located at a depth of $12 \mathrm{~m}$ and lodged under the feet of the southern reef of Ras alQalaat (Figs. 5.9 and 5.10).

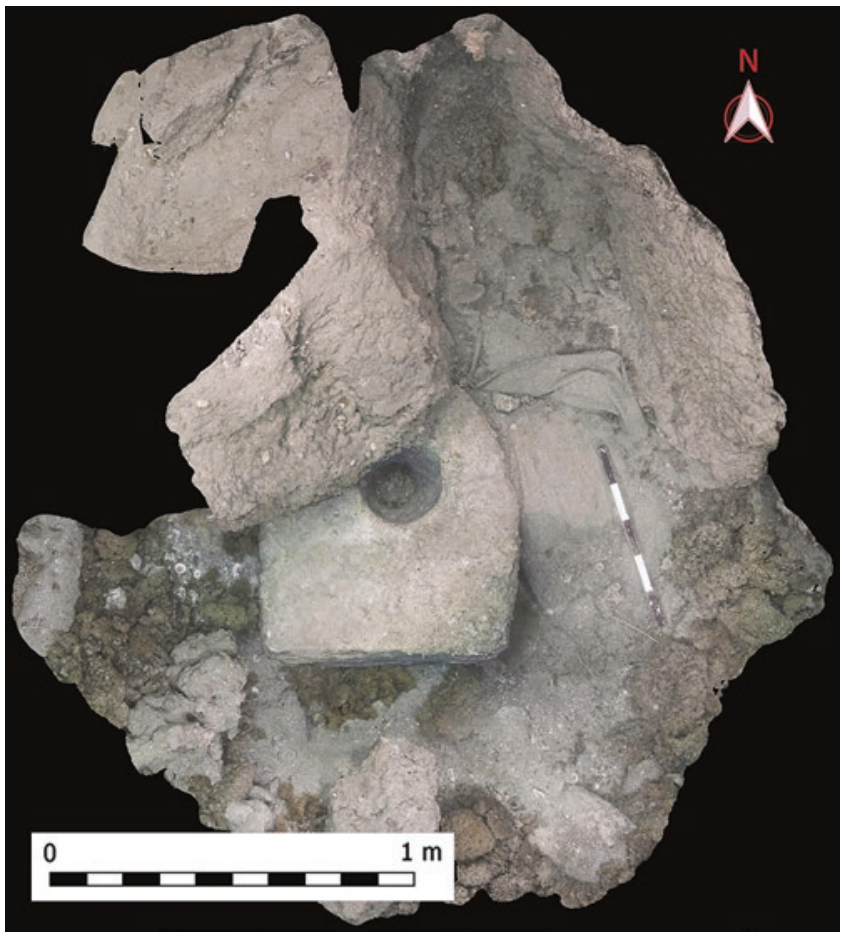

Fig. 5.9 Orthophoto of the anchor (AN.S12.004) found at the bottom of the southern reef of Ras al-Qalaat (M.S. Salama).

\subsubsection{The Groups of Anchors}

Four groups of anchors, all located scattered at the feet of the southern reef at a depth of 11-12 m below MSL and some 30-80 m from the coast, were surveyed photographically for multi-image photogrammetry (Fig. 5.10). Group 1 is located in Square S11 and includes four small-sized anchors, one of which was two-holed (AN.S11.273), with the rest being oneholed (AN.S11.286-288) (Fig. 5.11). Group 2 is located in Square S11 and includes four single-hole anchors of which two were quite large (AN.S11.292 and AN.S11.293) and the other two modest in size (AN.S11.291 and AN.S11.274) (Fig. 5.12). Group 3 is located in Square T11 and is comprised of seven single-hole anchors (AN.T11.294, 295, 296, 297, 298, 299, and 300) (Fig. 5.12). Group 4 consists of a single-holed anchor along with two stone mill elements (Anchor: AN.T10.146) (Fig. 5.13).

\subsubsection{The Isolated Masonry Blocks}

A few isolated blocks were recorded. These are mainly located to the south of Ras al-Qalaat. A rectangular block (AN.U9.240) was recorded in 2013 via GPS at a depth of $10.8 \mathrm{~m}$ about $100 \mathrm{~m}$ off the southern coast of the Anfeh vil- 


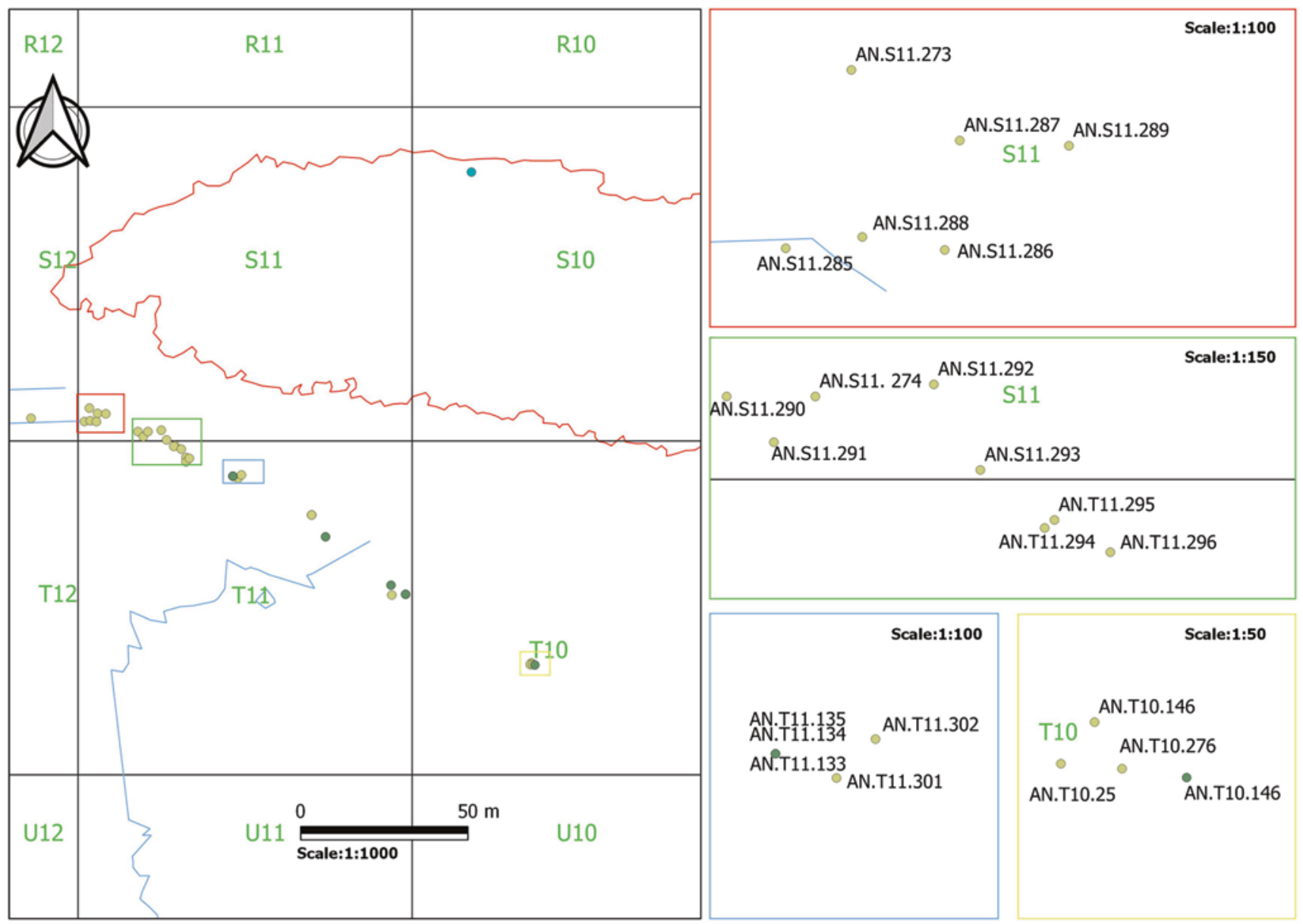

Fig. 5.10 Map of all the artefacts recorded during the surveys of 2013 and 2016 on the southern reef of Ras al-Qalaat (E. Cocca)

lage. It measures $1.98 \times 0.45 \times 0.30 \mathrm{~m}$. In 2016 , this masonry block was found completely covered under some $40 \mathrm{~cm}$ of sediments (Fig. 5.14) (Table 5.4). It was only partially uncovered as no excavation dredge was available.

\subsubsection{The Masonry Blocks in Groups}

\subsubsection{The North-Eastern Group}

This group of masonry blocks is located to the north-east of the Ras al-Qalaat, only a few metres offshore. It consisted of two clusters of blocks located at about $2 \mathrm{~m}$ from each other in Square S8. The first cluster is made of three rectangular blocks (AN.S8.185-187) and the second of five blocks (AN. S7.188-192) (Figs. 5.5 and 5.15), and at a maximum depth of $5 \mathrm{~m}$ (Table 5.4). The team established a reference grid for this area with four rods and a polygon of approximately $35 \mathrm{~m}$ of perimeter rope. The location of these clusters had been recorded with a GPS in 2013.

\subsubsection{The North-Western Group}

This large group of masonry blocks is located in Square R10 on the north-western side of Ras al-Qalaat slightly less than $50 \mathrm{~m}$ from the coast (Fig. 5.5). It stretches over an area about $30 \mathrm{~m}$ by $20 \mathrm{~m}$, dropping northwards from a depth of 3-13 m. These blocks vary in sizes and shapes; most of them do not seem to be worked, unless they were heavily weathered by the sea conditions (Fig. 5.16).

\subsubsection{The South-Eastern Group}

This group of masonry blocks is located to the south east end of the Ras al-Qalaat, spreading from the foot of the reef to only a few southwards, on a NW-SE axis (Figs. 5.5 and 5.17). It consisted of six spread-out blocks in Square T8 (AN.T8.175-178, 282, 305) and a close-range cluster of eight blocks in Square T9 (AN.T9.306-313). The blocks lay at a depth range of 3-5 $\mathrm{m}$. The location of these clusters had been recorded via GPS in 2013 and georeferenced with the total station through a set of control points in 2017. The study of this group of blocks is ongoing. 
Fig. 5.11 Orthophoto of Group 1 of anchors located at the bottom of the southern reef of Ras al-Qalaat (M.S. Salama)
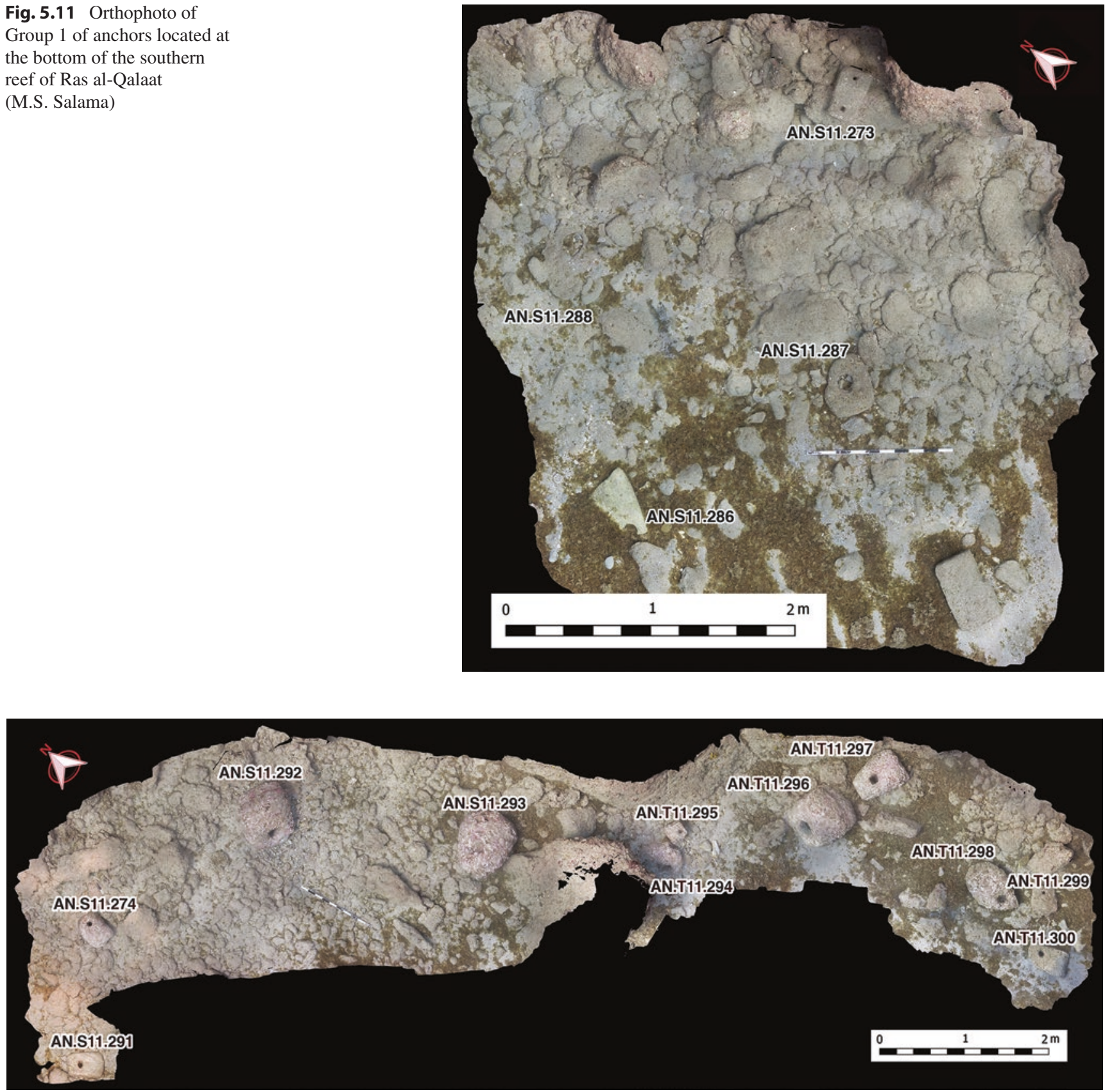

Fig. 5.12 Ortophotos of Groups 2 and 3 of anchors located at the bottom of the southern reef of Ras al-Qalaat (M.S. Salama)

\subsection{Accuracy}

\subsubsection{Accuracy of Georeferencing of the Survey}

The archaeological remains located at shallow depths of 3-5 m were recorded using a total station Nikon DTM-322 and a network of coded control points with absolute coordinates. These depths corresponded to the height of the pole holding the prism. The network of control points consisted of tagged square plastic sheets attached to lead weights to sit steadily on the seabed for the duration of the image capture and which were spread conveniently around the targeted areas to be photographed. All the coordinates recorded were georeferenced in the world projection system WGS 84/UTM zone 36N (EPSG: 32636). They were inserted in Agisoft Photoscan/Metashape respectively for each of their correspondent control points in order to tie the model into a known coordinate system. This set the data in the right geographic position and with the correct scale, and adjusted distortions in the models. 
Fig. $\mathbf{5 . 1 3}$ Orthophotos of Group 4 of anchors and mill located at the bottom of the southern reef of Ras al-Qalaat (M.S. Salama)
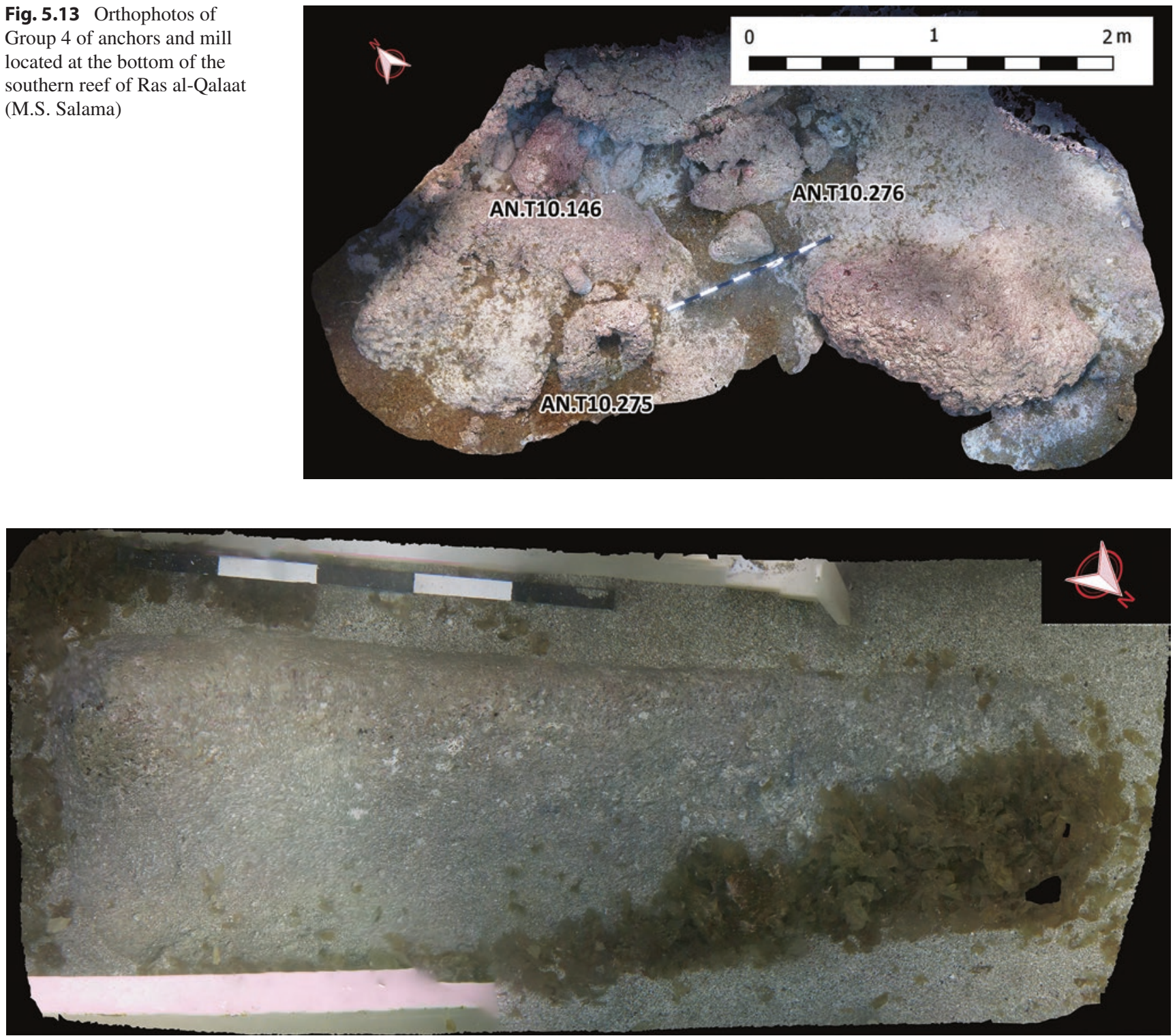

Fig. 5.14 Orthophoto of masonry block (AN.U9.240) located off of the southern coastline of Anfeh (M.S. Salama).

The master station was positioned on two previously established topographic benchmarks (points 2011 and 2009). Pt.2011 is a geodetic point that had been corrected from the height of 35.87-13.37 $\mathrm{m}$ above MSL using the formula by Courbon $(2016,263)$ 'Mean Sea level=Ellipsoidal height of the GPS-22.35 m.' Knowing the absolute coordinate of Pt.2009, the total station was oriented and then other control points (with absolute coordinate and height corrected) were fixed nearer to the features to be recorded such as the masonry blocks in R10, and T8-T9.

The coordinates of most of the submerged artefacts lying at depths greater than $5 \mathrm{~m}$ were recorded from the surface with a handheld GPS (Garmin eTrex 10) using small numbered buoys attached to the objects, during calm weather conditions to reduce error margins as much as possible. The accuracy of this GPS position was $3 \mathrm{~m}$ at the surface. The depth and orientation of artefacts was recorded using the wrist compass and dive computer. The wrist compass was an Oceanic SWIV calibrated for the Northern Hemisphere. The accuracy of the depth recorded by the dive computer is slightly variable due to the tidal range but it is considered fit for purpose in this case since it does not exceed a maximum of $0.45 \mathrm{~m}$.

Recording of the masonry blocks in R10 (Fig. 5.16) was undertaken using both methods. The shallow part of the masonry blocks were recorded with control points and the total station while the deeper parts were locked into GIS using GPS readings from the surface of a buoy tied to each rebar in calm weather. Depth of the blocks and rebars were taken using the dive computer under water. The authors are 
Fig. 5.15 Orthophoto of masonry blocks located north east of Ras al-Qalaat

(M.S. Salama)

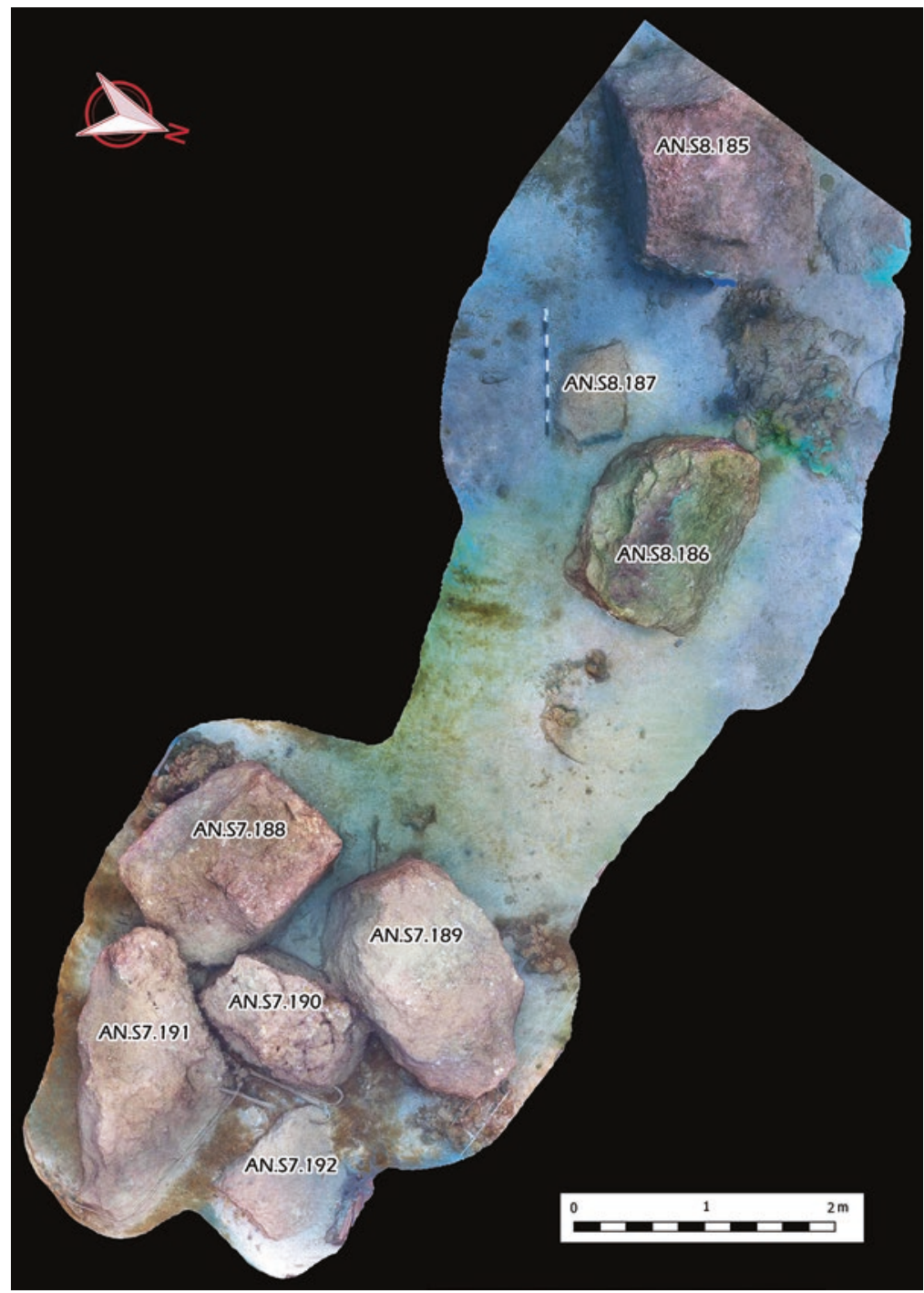

aware that such a method is not as accurate as the systematic use of control points. Nevertheless it mitigated potential error margins and improved the orientation and accuracy of the resulting models and orthophotos. It is, however, planned in future fieldwork seasons to return to mapped areas (whenever possible) and lock them within a network of control points, georeferenced using a total station.

\subsubsection{Accuracy of the Photogrammetric Survey}

In order to assess the internal accuracy of the photogrammetric survey, the authors tested results of digital measurements from 3D models against the classic recording method of taking 2D measurements in situ with a tape measure. All models were scaled in reference to the $1 \mathrm{~m}$ scale bar which was placed next to the objects prior to taking photographs. Anchors were measured systematically by both the diver and the archaeologist measuring from the 3D model, according to the maximum dimensions available, i.e. the highest numeric value of the length, width, thickness and hole(s) diameter of an anchor.

Table 5.5 compares the measurements of 17 anchors that were taken on the site by divers alongside corresponding measurements extrapolated from the 3D models of these anchors. The comparisons show generally relative negligible differences of $1-3 \mathrm{~cm}$ between the two sets of measurements. Two discrepancies of over $3 \mathrm{~cm}$ were ascribed to human error rather than the accuracy of the photogrammetric models.

\subsection{Challenges}

The main set of challenges for underwater photography relates to the operational environment. Parameters such as visibility under water, differential light absorption and colour 


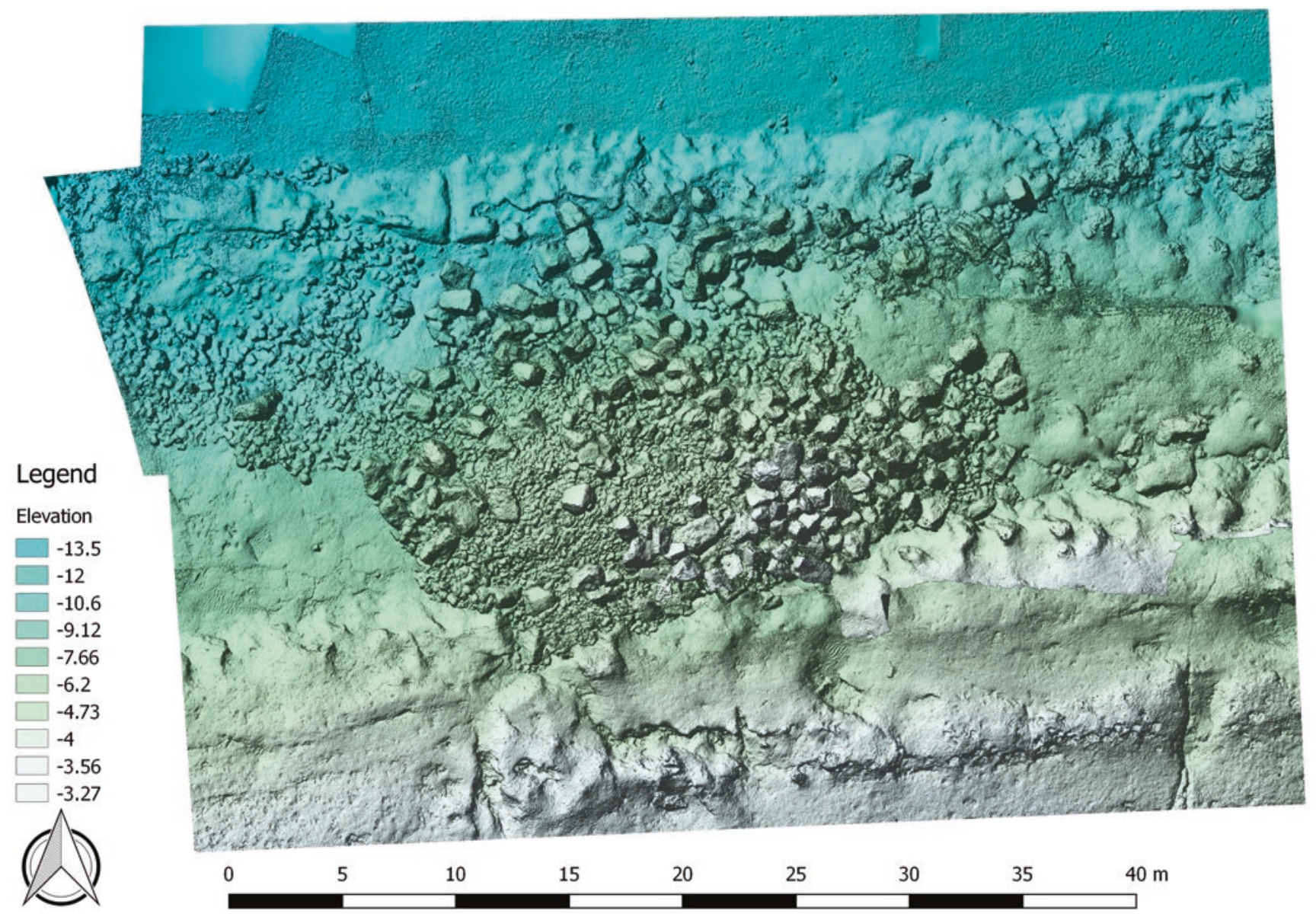

Fig. 5.16 DEM of submerged masonry blocs located to the northwest side of Ras al-Qalaat in square R10 (E. Cocca)

Fig. $\mathbf{5 . 1 7}$ Orthophoto of masonry blocs located to the southeast side of Ras al-Qalaat in squares T8 and T9 (E. Cocca). 1: AN.T9.311, 2: AN.T9.310, 3: AN.T9.309, 4: AN.T9.308, 5: AN.T9.307, 6: AN.T9.306, 7: AN.T9.313, 8: AN.T9.312, 9: AN.T8.305, 10: AN.T8.176, 11: AN.

T8.175, 12: AN.T8.282, 13: AN.T8.178, 14: AN.T8.177

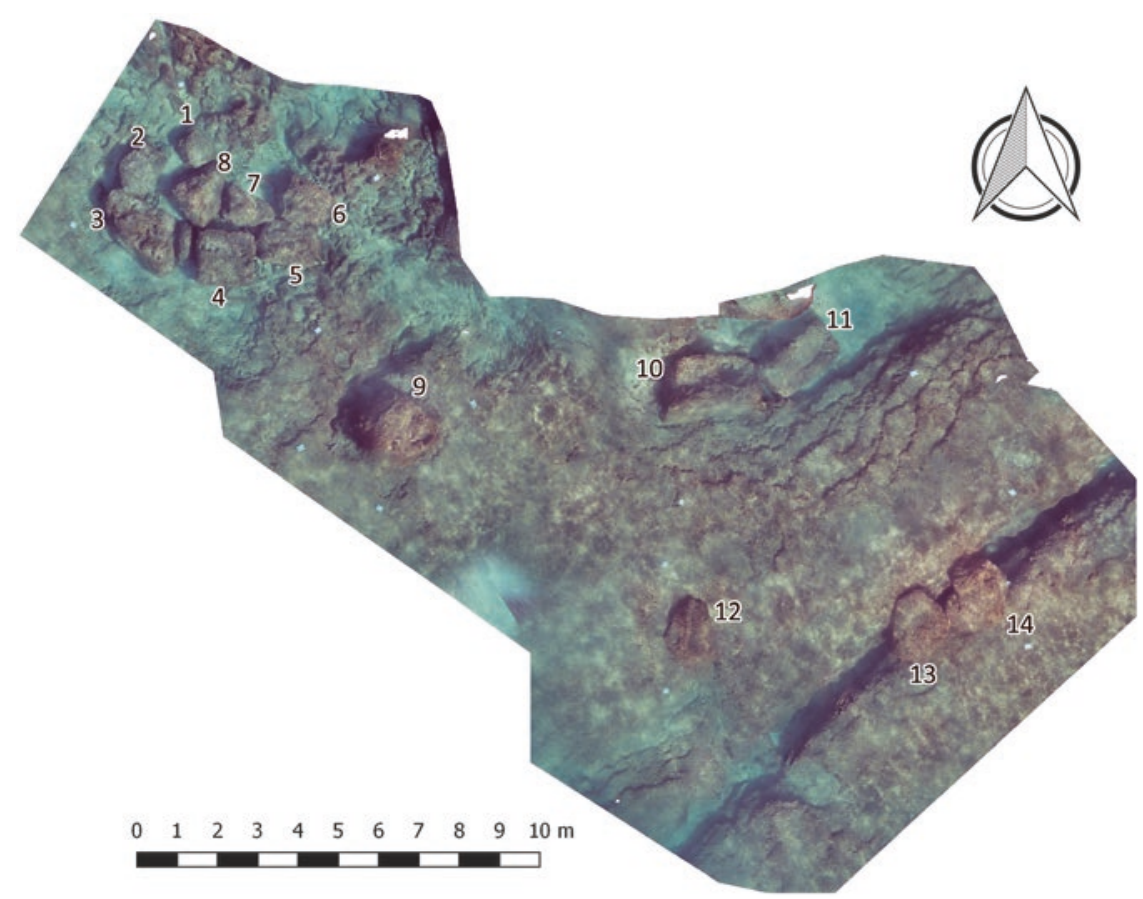


Table 5.5 Comparisons of measurements recorded on site by the divers with those taken from the 3D models. N/A is given for missing values, meaning that no comparison could be carried out

\begin{tabular}{|c|c|c|c|c|c|}
\hline Anchor & & Length $(\mathrm{cm})$ & Width $(\mathrm{cm})$ & Thickness $(\mathrm{cm})$ & Hole \\
\hline AN. S12 004 & & 73 & 65 & 37.5 & 24 \\
\hline AN. S12 004 & $3 \mathrm{D}$ & 71.8 & 65.8 & 36 & 22 \\
\hline Difference & & 1.2 & -0.8 & 1.5 & 2 \\
\hline AN.S11.273 & & 30 & 18 & N/A & N/A \\
\hline AN.S11.273 & $3 \mathrm{D}$ & 35.7 & 20.8 & 5.8 & $4.6-4.1$ \\
\hline Difference & & -5.7 & -2.8 & N/A & $6.4-7.9$ \\
\hline AN.S11.286 & & 46 & 30 & 8 & 9 \\
\hline AN.S11.286 & 3D & 46.7 & 27.2 & 7.02 & 9.4 \\
\hline Difference & & -0.7 & 2.8 & 0.98 & -0.4 \\
\hline AN.S11.287 & & 47 & 32 & 4 & 11 \\
\hline AN.S11.287 & $3 \mathrm{D}$ & 46 & 31.3 & 4.9 & 12.3 \\
\hline Difference & & 0.98 & 0.7 & -0.9 & -1.3 \\
\hline AN.S11.288 & & 47 & 29 & 6 & 16 \\
\hline AN.S11.288 & $3 \mathrm{D}$ & 47.2 & 30.1 & 4.8 & 16.4 \\
\hline Difference & & -0.2 & -1.1 & 1.2 & -0.4 \\
\hline AN.S11.274 & & 40 & 30 & N/A & N/A \\
\hline AN.S11.274 & 3D & 42.5 & 31.5 & 11.5 & 5.3 \\
\hline Difference & & -2.5 & -1.5 & N/A & N/A \\
\hline AN.S11.291 & & 42 & 30 & 9.5 & N/A \\
\hline AN.S11.291 & $3 \mathrm{D}$ & 45 & 30 & 10.5 & 8.5 \\
\hline Difference & & -3 & 0 & -1 & N/A \\
\hline AN.S11.292 & & 78 & 57 & 32 & 20 \\
\hline AN.S11.292 & $3 \mathrm{D}$ & 77.8 & 58.5 & 30.8 & 17.2 \\
\hline Difference & & 0.2 & -1.5 & 1.2 & 2.8 \\
\hline AN.S11.293 & & 78 & 65 & 34 & $29 \times 22$ \\
\hline AN.S11.293 & $3 \mathrm{D}$ & 76 & 64.6 & 35 & $29.1 \times 20.3$ \\
\hline Difference & & 2 & 0.4 & -1 & $0.1 \times 1.7$ \\
\hline AN.T11.294 & & 46 & 51 & 15 & 21 \\
\hline AN.T11.294 & 3D & 49 & 51.95 & 14.5 & 20.8 \\
\hline Difference & & -3 & -0.95 & 0.5 & 0.2 \\
\hline AN.T11.295 & & 24.6 & 19.3 & 10 & 6 \\
\hline AN.T11.295 & 3D & 23.6 & 20.1 & 12.5 & 4 \\
\hline Difference & & 1 & -0.8 & -2.5 & 2 \\
\hline AN.T11.296 & & 69 & 60 & 31 & 25.8 \\
\hline AN.T11.296 & 3D & 67.2 & 63.3 & 33 & 22.9 \\
\hline Difference & & 1.8 & -3.3 & -2 & 2.9 \\
\hline AN.T11.297 & & 63 & 41.6 & 22 & 14.6 \\
\hline AN.T11.297 & $3 \mathrm{D}$ & 64.3 & 41.5 & 20 & 14 \\
\hline Difference & & -1.3 & 0.1 & 2 & 0.6 \\
\hline AN.T11.298 & & 71.3 & 48.2 & 12.7 & 12.9 \\
\hline AN.T11.298 & 3D & 73.8 & 47 & 15.5 & 12.4 \\
\hline Difference & & -2.5 & 1.2 & -2.8 & 0.5 \\
\hline AN.T11.299 & & 38 & 30 & 6.6 & 5 \\
\hline AN.T11.299 & 3D & 37.9 & 31 & 7.2 & 4.5 \\
\hline Difference & & 0.1 & -1 & -0.6 & 0.5 \\
\hline AN.T11.300 & & 46 & 28 & 8.5 & 9 \\
\hline AN.T11.300 & $3 \mathrm{D}$ & 50 & 30 & 7.9 & 8.3 \\
\hline Difference & & -4 & -2 & 0.6 & 0.7 \\
\hline AN.T10.146 & & 60 & 40 & 20 & 10 \\
\hline AN.T10.146 & $3 \mathrm{D}$ & 57.6 & 38.8 & 19.7 & 9.9 \\
\hline Difference & & 2.4 & 1.2 & 0.3 & 0.1 \\
\hline
\end{tabular}




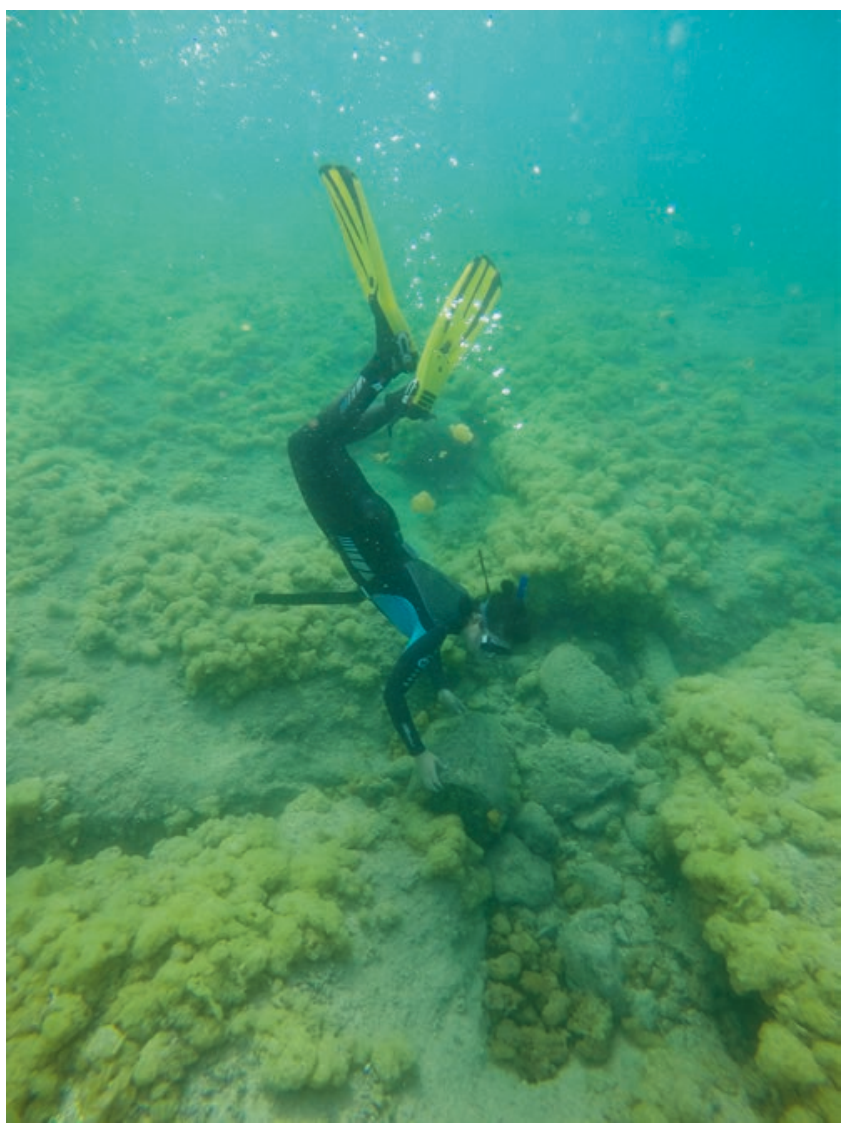

Fig. 5.18 Team member Clara Fuquen examining a masonry element among the algae covering the sea-bottom (Z. Morsy)

loss, capture and dive time at a given depth, and optical distortion due to the lens/water interface, all needed to be mitigated. Optical noise created by moving elements such as fish, floating algae transport and movement, and sediment particles in suspension resulting in substantial backscatter interfered with the process. Anfeh's seabed is covered with fine sediments of clay and sand that become disturbed under the slightest movement. The authors needed to operate with utmost care during the capturing process. Most of the time the photographer needed to keep a near-vertical position with their legs up. Also, the targeted areas of the seabed and especially the masonry blocks were covered to a great extent by a vegetation of Colpomenia sinuosa, a type of brown algae (Fig. 5.18), since the diving took place in springtime. These were cleared prior to every survey to enhance visibility and quality of the recording. The process of cleaning large masonry blocks was a tedious one, consuming dive time, and extra care needed to be taken for safety from the presence of bearded fire-worms (Hermodice carunculata), which are harmful to people.

Considering that the team was limited in number, and the areas surveyed quite extensive, a considerable amount of recording was accomplished in under a month of fieldwork, through the use of 3D techniques. Only one to two dives dedicated to collecting images for the photogrammetric process was possible each day. Dive teams were formed by two divers with one boat operator on the surface for safety. Depending on the time of day, currents, amounts of sediments and algae, the first available teams of the day would dedicate their dives to cleaning archaeological finds and features; while the divers responsible for photographing had to wait until the debris settled in order to proceed. In certain parts of the seabed, such as at the foot of the southern reef midway across the Ras al-Qalaat, the brown algae formed a floating layer, completely covering the anchors. Although an airlift could have cleared this layer, the lack of this equipment at the time meant that some anchors could not be recorded through underwater photogrammetry.

Weather and sea conditions were not always kind. At times, the divers were faced with strong currents under water that made photographic documentation difficult. This caused some delays since the divers had to pause several times to adjust their position during capture. Also, the underwater visibility deteriorated as the surface surge and underwater swell got stronger, which at times prevented the team from finishing the task at hand. Moreover, the sedimentation rate on the sea-bed of Ras al-Qalaat and adjacent coasts is high. This meant that several finds that had been located during the 2013 underwater survey were either completely or partially buried in sand. As mentioned, the team was only able to partially unearth the masonry block (AN.U9.240), which prevented them from obtaining a complete $3 \mathrm{D}$ model of the block. In regard to the post-processing phase of the photogrammetric survey, analyses of the images collected and production of digital models was time-consuming due to staff availability and computer processing requirements and some of the models are still being finalised.

\subsection{Discussion and Conclusions}

Although the application of photogrammetry has become almost universally adopted in maritime archaeology, this project is the first endeavour of its kind in Lebanon where the research team has demonstrated the impact of 3D photogrammetry on archaeological practice in a marine environment. Despite the limitations and constraints detailed above, the authors found these methods practical for documenting sites where more expensive equipment and methods are not available. The technique also has the advantage, among other diver-based recording methods, to minimize time spent under water compared to manual methods of $2 \mathrm{D}$ and/or trilateration. As shown in Table 5.5, measurements from photogrammetry helps in mitigating human errors taken through these traditional real-time measurements while operating in a challenging environment where currents, visibility and 
depth might impair human judgment and perception of accuracy.

Moreover, underwater photogrammetry is a non-intrusive technique of investigation to extract, integrate, and share archaeological data from 1-to-1 scale 3D models without having to revisit the actual sites (Yamafune et al. 2016, 4). At Anfeh, the authors were able-through the implementation of a time and cost-effective methodology-to capture 3D measurements of submerged artefacts. Having mapped isolated finds as well as their wider underwater context, the 3D photogrammetry offered the possibility of viewing these sites in their entirety that would have otherwise been observed fragmentarily. The authors have effectively gathered a solid baseline of knowledge of Anfeh's seabed, with substantial documentation on which to build further research and interpretation of the site.

Much of the archaeological analysis and interpretation of the archaeological results from the underwater photogrammetry campaigns are still under way. These campaigns form part of the wider research of a program aimed at Anfeh's maritime cultural landscape. However, some preliminary remarks can be made here about the contribution of these surveys to the wider project. As well as allowing a better understanding of the seabed topography and material, the 3D surveys have bridged the physical limitation between land and sea, clearly illustrating the seamlessness connection of the submerged archaeology with the promontory of Ras alQalaat. The presence on the south side of Ras al-Qalaat (Fig. 5.10) of a substantial amount of anchors varying in size suggests that this southern reef might have been a popular anchorage location in antiquity, positioned as it is in the lee of the northerly winds. The presence of rock-cut ways of access and stairways on the peninsula's southern face might also indicate that goods were transferred to the shore from boats laying at anchor. The 3D models of anchors have allowed detailed measurement as well as more accurate volumetric and weight estimation. This helps to establish their typology and improves our understanding of their spatial distribution and positioning. Significantly, the estimation of anchor weight can inform the interpretation of ship sizes and types.

The masonry blocks are still under study at the time of writing. However, from a preliminary analysis, it seems that the blocks located in areas S7 and S8 in the north and T8, T9, and U9 south of Ras al-Qalaat, might have been once part of the medieval fortress that stood on the promontory. ${ }^{8}$ Some of these have dimensions and shapes that indicate they might have been carved from the quarries on the promontory itself (Abdul Massih 2016). Their presence under water can be explained through two factors: (1) the collapse of built stone architecture on the promontory due to tectonics and weather

\footnotetext{
${ }^{8}$ For details on this fortress see Chaaya (2016).
}

conditions; or (2) the dismantling and transfer from the promontory to meet the construction needs of the modern village of Anfeh, and/or further afar to the city of Tripoli which is located some $15 \mathrm{~km}$ north of Anfeh. As for the large cluster of masonry blocks mapped in Square R10 at the north-western side of the promontory, these might have functioned as a breakwater to shelter the access to the peninsula at some point in time. Research into these blocks is ongoing.

Finally, use of underwater photogrammetry at Anfeh has great potential for public outreach for underwater archaeology in Lebanon. Indeed, one of the future objectives of the research project at Anfeh is to provide virtual access to the underwater world by creating a fly-through video of the anchor area that can be uploaded to the internet. This will help to generate social significance for underwater archaeology, disseminate knowledge, and raise awareness of the importance of Anfeh's underwater cultural heritage.

Acknowledgements The authors would like to extend their gratitude to the Ministry of Culture and the Directorate General of Antiquities of Lebanon; the Honor Frost Foundation for funding the principal author's postdoctoral fellowship; Nadine Haroun-Panayot, head of the Department of Archaeology and Museology at the University of Balamand (UoB), for entrusting the team with this task; the Institute of Environment at UoB for the bathymetry map; the Department of Civil \& Environmental Engineering at $\mathrm{UoB}$ for lending the team the total station; Crystal Safadi for all things GIS-related and map production; Enzo Cocca for GIS, photogrammetry, database services and his valuable comments on parts of this draft; Ralph Pedersen for his kind advice on and review of earlier drafts; and finally to the other team members without whom this and other endeavours at Anfeh would not have been possible in the past years: Samer Amhaz, Mohammad Azzam, Rupert Brandmeier, Enzo Cocca, Hadi Choueiri, Salvatore Colella, Clara Fuquen, Dylan Hopkinson, Menna-Allah Ibrahim, Mario Kozaily, Ziad Morsy, Lorine Mouawad, Julian Jansen van Rensburg, Crystal Safadi, Serge Soued, and Maii Tarek.

\section{References}

Abdul Massih J (2016) Notes sur les carrières maritimes d'Enfeh. In: Panayot-Haroun N (ed) Mission archéologique d'Enfeh: résultats préliminaires des travaux de prospection et de fouille de 2011 à 2015, 16. Direction Générale des Antiquités, Beirut, pp 285-287

Agisoft (2016) Agisoft photoscan user manual: professional edition. http://www.agisoft.com/pdf/photoscan-pro_1_2_en.pdf. Version 1.2. Accessed 27 Oct 2017

Balletti C et al (2015) Underwater photogrammetry and 3D reconstruction of marble cargos shipwreck. Int Arch Photogramm Remote Sens Spat Inf Sci XL-5(W5):7-13. Available at: http://www.int-archphotogramm-remote-sens-spatial-inf-sci.net/XL-5-W5/7/2015/

Balletti C, Beltrame C, Costa E, Guerra F, Vernier P (2016) 3D reconstruction of marble shipwreck cargoes based on underwater multiimage photogrammetry. Digit Appl Archaeol Cult Herit 3(1):1-8. https://doi.org/10.1016/j.daach.2015.11.003

Bruno F, Lagudi A, Gallo A, Muzzupappa M, Davidde Petriaggi B, Passaro S (2015) 3D documentation of archaeological remains in the underwater park of Baiae. Int Arch Photogramm Remote 
Sens Spat Inf Sci XL-5(W5):41-46. https://doi.org/10.5194/ isprsarchives-XL-5-W5-7-2015

Capra A, Dubbini M, Bertacchini E, Castagnetti C, Mancini F (2015) $3 \mathrm{~d}$ reconstruction of an underwater archaeological site: comparison between low cost cameras. Int Arch Photogramm Remote Sens Spat Inf Sci XL-5/W5:67-72. https://doi.org/10.5194/ isprsarchives-XL-5-W5-67-2015

Chaaya A (2016) Le château médiéval d’Enfeh. In: Panayot-Haroun $\mathrm{N}$ (ed) Mission archéologique d'Enfeh: résultats préliminaires des travaux de prospection et de fouille de 2011 à 2015, Bulletin d'archéologie et d'architecture Libanaises, vol 16. Direction Générale des Antiquités, Beirut, pp 281-283

Costa E, Beltrame C, Guerra F (2015) Potentialities of 3D reconstruction in maritime archaeology. In: Giligny F, Djindjian F, Costa L, Moscati P, Robert S (eds) Concepts, methods and tools: proceedings of the 42nd annual conference on computer applications and quantitative methods in archaeology. Archaeopress, Oxford, pp 549-556

Courbon P (2016) L'étude topographique. In: Panayot-Haroun N (ed) Mission archéologique d'Enfeh: résultats préliminaires des travaux de prospection et de fouille de 2011 à 2015, Bulletin d'archéologie et d'architecture Libanaises, vol 16. Direction Générale des Antiquités, Beirut, pp 262-263

Drap P (2012) Underwater photogrammetry for archaeology. In: Carneiro Da Silva P (ed) Special applications of photogrammetry. IntechOpen, pp 111-136. https://doi.org/10.5772/33999

Drap P, Merad D, Hijazi B, Gaoua L, Saccone MMNM, Chemisky B, Seinturier J, Sourisseau J-C, Gambin T, Castro F (2015) Underwater photogrammetry and object modeling: a case study of Xlendi wreck in Malta. Sensors 15:30351-30384. https://doi.org/10.3390/ s151229802

Frost H (1997) Stone anchors: the need for methodical recording. Indian J Hist Sci 32(2):121-126

Fulton C, Viduka A, Hutchison A, Hollick J, Woods A, Sewell D, Manning S (2016) Use of photogrammetry for non-disturbance underwater survey - an analysis of in situ stone anchors. Adv Archaeol Pract 4(1):17-30

Gawlik N (2014) 3D modelling of underwater archaeological artefacts. MA Thesis, Norwegian University of Science and Technology

Green J, Matthews S, Turanli T (2002) Underwater archaeological surveying using photo modeler, virtual mapper: different applications for different problems. Int J Naut Archaeol 31(2):283-292. https:// doi.org/10.1006/ijna.2002.1041
Lawrence TE (1988) Crusader castles. Clarendon, Oxford University Press, New York

McCarthy J (2014) Multi-image photogrammetry as a practical tool for cultural heritage survey and community engagement. J Archaeol Sci 43:175-185. https://doi.org/10.1016/j.jas.2014.01.010

McCarthy J, Benjamin J (2014) Multi-image photogrammetry for underwater archaeological site recording: an accessible, diver-based approach. J Marit Archaeol 9(1):95-114

Nordiguian L, Voisin JC (1999) Châteaux et églises du Moyen Age au Liban. Editions Terre du Liban/Trans-Orient, Beyrouth

Panayot-Haroun N (2015) Anfeh unveiled: historical background, ongoing research and future prospects. J East Mediterr Archaeol Herit Stud 3(4):396-415

Panayot-Haroun N (2016) Mission archéologique d'Enfeh. PanayotHaroun N Mission archéologique d'Enfeh: résultats préliminaires des travaux de prospection et de fouille de 2011 à 2015, 16. Beirut, Direction Générale des Antiquités, 255-294

Polzer M, Casaban J (2012) Photogrammetry: a legacy of innovation reaching back to Yassiada. INA Q 39(1/2):13-17

Semaan L (2016) Surveying the waters of Anfeh: preliminary results. Skyllis 16(1):54-67

Semaan L, Fuquen C, Hopkinson D, Jansen Van Rensburg J, Morsy Z, Safadi C (2016) The underwater visual survey at Anfeh. PanayotHaroun N Mission archéologique d'Enfeh: résultats préliminaires des travaux de prospection et de fouille de 2011 à 2015, 16. Beirut, Direction Générale des Antiquités, 287-291

Skarlatos D, Demesticha S, Kiparissi S (2012) An 'open' method for $3 \mathrm{~d}$ modelling and mapping in underwater archaeological sites. Int J Herit Digit Era 1(1):1-24

Skarlatos D, Demesticha S, Neophytou A (2014) The 4th century BC shipwreck at Mazotos, Cyprus: new techniques and new methodologies in the 3D mapping of shipwreck excavations. J Field Archaeol 39(2):134-150. https://doi.org/10.1179/00934690 14Z.00000000077

Van Damme T (2015) Computer vision photogrammetry for underwater archaeological site recording in a low-visibility environment. Int Arch Photogramm Remote Sens Spat Inf Sci XL-5/W5:231-238. https://doi.org/10.5194/isprsarchives-XL-5-W5-231-2015

Yamafune K, Torres R, Castro F (2016) Multi-image photogrammetry to record and reconstruct underwater shipwreck sites. J Archaeol Method Theory 24(3):703-725. https://doi.org/10.1007/ s10816-016-9283-1

Open Access This chapter is licensed under the terms of the Creative Commons Attribution 4.0 International License (http://creativecommons. org/licenses/by/4.0/), which permits use, sharing, adaptation, distribution and reproduction in any medium or format, as long as you give appropriate credit to the original author(s) and the source, provide a link to the Creative Commons licence and indicate if changes were made.

The images or other third party material in this chapter are included in the chapter's Creative Commons licence, unless indicated otherwise in a credit line to the material. If material is not included in the chapter's Creative Commons licence and your intended use is not permitted by statutory regulation or exceeds the permitted use, you will need to obtain permission directly from the copyright holder. 